Apidologie, 1979, 10 (2), 175-209.

\title{
UNTERSUCHUNGEN ZUM BAUVERHALTEN DER HONIGBIENE* (APIS MELLIFICA)
}

\author{
Recherches sur le comportement de construction de l'abeille \\ (Apis mellifica)
}

\author{
Gabriele von OELSEN und Eva RADEMACHER \\ Institut für Allgemeine Zoologie, Freie Universität Berlin \\ Königin-Luise-Strasse I-3, D- 1000 Berlin 33 (B.R.D.)
}

\begin{abstract}
SUMMARY
STUDIES ON THE BUILDING BEHAVIOUR OF THE HONEYBEE ( $A$ PIS MELLIFICA)
\end{abstract}

The comb-building behaviour of honeybees is investigated in reference to different cell arrangements of the honey-comb : Cells with two parallel walls vertically, cells with two walls horizontally, and cells arranged in a so-called flower pattern (" Blümchenmuster ", i. e. the cell arrangement is not similar on both sides of the comb). It was to learn whether a specific cell arrangement is innate or partly in consequence of learning processes. Furthermore, in how far is the force of gravity involved in comb construction?

Young bees hatched from combs with different cell arrangement had to build cells from unstamped strips of foundation. From these experiments a comparison of the results proves that learning processes are greatly involved. Tests, in which differently stamped strips of foundation are provided, indicate the adaptability of constructing bees to given patterns. However, this adaptability gradually depends on the season.

Experiments resulting in built combs with "flower pattern" raise the discussion : To what extent are cell walls a mould for further cell construction?

Tests are described in which bees built their combs from bottom to top ("Mauern ") : Under these conditions in fifty per cent of the combs a gradual change in the cell arrangement took place, probably because of the changed reference towards the force of gravity.

Young bees reared in round cells of artificial combs in horizontal position are tested for their combbuilding behaviour : For lack of a reference between comb, cell arrangement and force of gravity those bees do not construct combs.

(*) Zusammenfassung der Diplomarbeiten beider Autorinnen, Freie Universität Berlin 


\section{ZUSAMMENFASSUNG}

Das Bauverhalten von Bienen bei der Anlage unterschiedlicher Wabenmuster (Zellen in Spitzstellung, Querstellung und Blümchenmuster) wurde untersucht. Dabei sollte herausgefunden werden, ob die Musteranlage angeboren oder ob und unter welchen Bedingungen ein Erlernen möglich ist. Ausserdem wurde untersucht, inwieweit die Schwerkraft einen Einfluss auf die Musterausrichtung beim Wabenbau hat.

Jungbienen, aus unterschiedlich gemusterten Zuchtwaben geschlüpft, bauten ungeprägte Leitstreifen aus. Ein Vergleich der Bauergebnisse dieser Völker mit dem Zuchtwabenmuster zeigt, dass Lernprozesse beim Wabenbau eine Rolle spielen. Versuche mit unterschiedlich geprägten Leitstreifen machen die Anpassungsfähigkeit der Bienen an vorhandene Bausituationen deutlich. An altersmässig normal zusammengesetzten Völkern zeigt sich eine jahreszeitliche Abhängigkeit.

Aufgrund von Versuchen zur Entstehung einer Blümchenmusterwabe wird diskutiert, inwieweit beim Fortführen dieses Musters die Zellwände als mustergebende Elemente der Wabe von Bedeutung sind.

Unter experimentellen Bedingungen konnte ein Bauen von unten nach oben ( ( Mauern ») erreicht werden. Dabei trat in $50 \%$ der so entstandenen Wabenteile eine Änderung der Zellstellung ein, was eventuell auf den veränderten Bezug zur Schwerkraft zurückzuführen ist.

Das Bauverhalten von Jungbienen, aus horizontalen Waben mit runden Zellen geschlüpft, wird beschrieben. Bienen, die keinen Bezug von Wabe und Zellstellung zur Schwerkraft herstellen konnten, bauten nicht.

\section{EINLEITUNG}

\section{I. - Geschichtlicher Abriss}

Der Wabenbau der Honigbiene ist bisher unter unterschiedlichsten Aspekten untersucht worden. Aufgrund der Berechnungen von KePLer (1619) und MARALDI (1712) wurde die Bienenzelle für lange Zeit als Idealgebilde angesehen. Erst VoGT (1911) zeigte anhand sorgfältiger Messungen, dass beim Wabenbau durchaus Abweichungen von den Idealwerten auftreten. Mit der Geometrie der einzelnen Bienenzelle befassten sich Quelle (1923), SCHRöDER (1950) und SCHUSTER (1956). POHL (1939) und MereTz (1963) berechneten die Stabilität des Zellgefüges. Neben der Symmetrie der Bienenzelle wurde ihre Stellung im Gesamtverband an natürlichen Waben beschrieben (Wedmore 1929, Thompson 1930, Von Hessberg 1955, HubBe 1957). Von der Norm abweichende Waben stellten Armbruster (1920) und MaibaCH (1935) vor.

Huber (1814), Weiss (1958), LaU (1959) und UlRiCh (1964) beschreiben die Entstehung der Wabe : Besondere Bedeutung messen sie der Bautätigkeit am Anfang der Wabe und am Rand der Bauzunge zu. Bauen in entgegengesetzter Richtung, nämlich von unten nach oben, beobachteten Huber (1814) und SENdLer (1940).

GoNTARSKI (1949) konnte durch Rotationsversuche beweisen, dass die vertikale Ausrichtung der Waben und Wabenzellen nach der Schwerkraft erfolgt, was ein gutes Lageorientierungsvermögen des Einzeltieres voraussetzen muss. LINDAUER und NEDEL (1959) wiesen schliesslich die Rolle des Nackenorgans als Schweresinnesorgan nach. 
MARKL (1966) gelang eine Dressur von Bienen auf bestimmte Winkel zur Lotrechten. Bei Dressurversuchen im horizontalen und vertikalen Labyrinth bewies KaLMus (1937), dass sich Bienen anhand von Marken, die in Beziehung zur Richtung der Schwerkraft gesetzt werden, sowie an der Beschaffenheit der Unterlage und der Enge der Durchlaufkanäle orientieren können.

Martin und Lindauer (1966) beschreiben, dass Bienen mit Hilfe der Mandibeln und Antennen in der Lage sind, die Zellwandstärke zu messen. Die Antennen spielen aber keine Rolle bei der Anlage der Zellen in bezug auf den Zelldurchmesser und bei der Einordnung der Zellwände in den $120^{\circ}$ - Winkel. Das Nackenorgan der Biene ist das massgebliche, wenn nicht ausschliessliche Kontrollorgan bei der Orientierung der Wabe und der Wabenzellen im Schwerefeld (Martin und Lindauer 1966).

\section{II. - Problemstellung}

Betrachtet man freigebaute Waben, so ist die Zellstellung gar nicht so einheitlich, wie sie auf den ersten Blick erscheint. Neben der "normalen " Spitzstellung (Abb. 1a) treten auch Zellen in Querstellung (Abb. 1c) und Schrägstellung (Abb. $1 b$ ) auf; allen gemeinsam ist das Sechseck der Zellen. Sämtliche Zellstellungen können von einem Volk gebaut werden und kommen manchmal auch auf einer Wabe vor. Spitzstellung ist bei frei gebauten Waben die häufigste Zellstellung, das heisst die Hauptachse der Zellen deckt sich im Idealfall mit der Vertikalen. Spontan tritt in ca. $5 \%$ der Bauten Querstellung auf, wobei die Hauptachse der Zellen im Idealfall einen Winkel von $30^{\circ}$ zur Vertikalen bildet. Es kommen auch alle Übergänge zwischen diesen beiden Zellstellungen vor (Schrägstellung). In sehr seltenen Fällen tritt eine Mischform aus der Spitz- und Querstellung auf. Eine Seite der Wabe entspricht der normalen Spitzstellung, die andere Seite weist ein um $30^{\circ}$ gedrehtes Zellstellungsmuster auf. Daraus, wie aus jeder anderen Verdrehung der Zellstellung beider Seiten gegeneinander, ergibt sich ein Zellgrundmuster, das verschiedene Zellgrundtypen in regelmässiger Wiederholung enthält. Dieses Wabenmuster wird als " Blümchenmuster » bezeichnet : Bei Durchlicht wird ein Wabenmuster sichtbar, bei dem zwei Zellböden genau übereinander liegen und damit das Blütenzentrum bilden. Die benachbarten Zellen erscheinen durch die Zellverschiebung wie "Blütenblätter » (Abb. 1d).

Nach Martin und Lindauer (1966) sind Bienen mit Hilfe des Nackenorgans in der Lage, sich über die Stellung der Wabenzellen und der Gesamtwabe in bezug zur Schwerkraft zu orientieren. Inwieweit Lernprozesse eine Rolle spielen und Bienen das "Schlüpfmuster " bei ihrer Bautätigkeit benutzen, wurde in der vorliegenden Arbeit untersucht.

Innerhalb eines Volkes schlüpfen Bienen unter Umständen aus verschiedenen Wabenmustern. Passen sich diese Bienen bei ihrer eigenen Bautätigkeit an andere bereits begonnene Muster an, um zu einer Einheitlichkeit zu gelangen?

Bei der Enstehung der Wabe muss innerhalb der Bautraube eine Verständigung über die Bausituation möglich sein. Die Versuche sollten klären, ob erschwerte 
a. Spitzstellung

a: disposition verticale

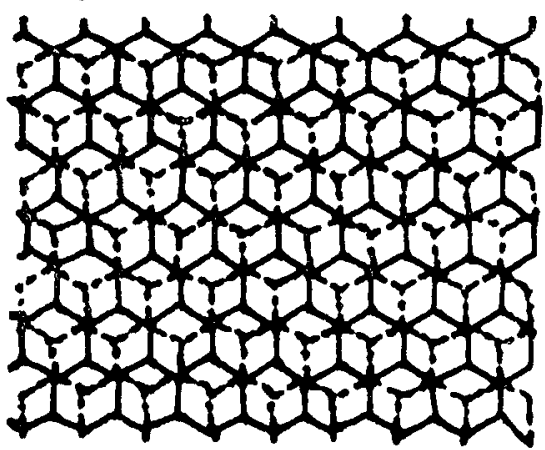

c. Querstellung

$c:$ disposition transversale

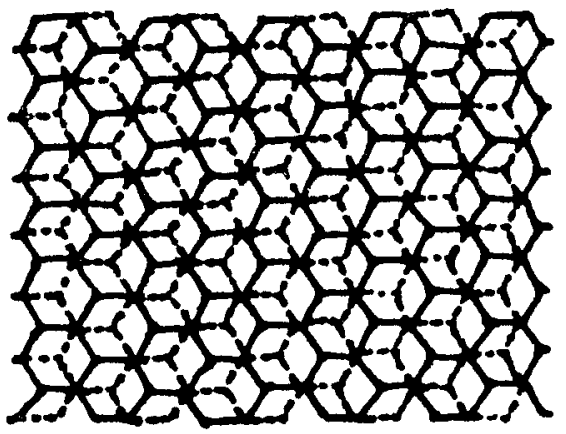

b. Schrägstellung

$b$ : disposition oblique

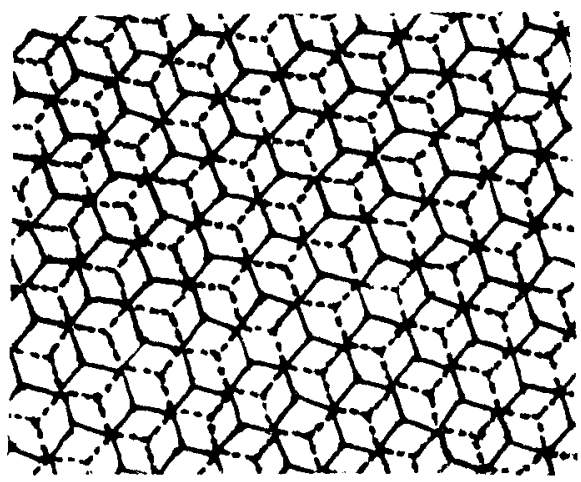

d. Blümchenmuster

d: configuration florale

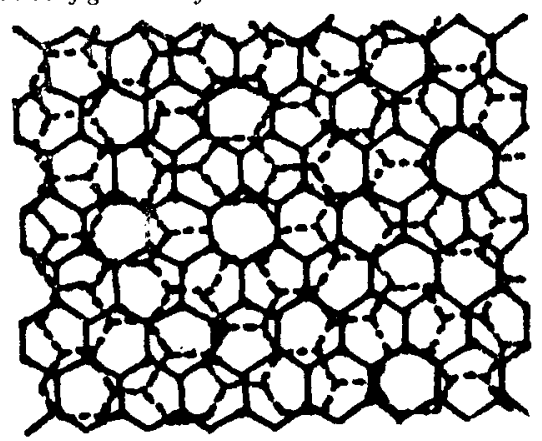

Aвв. 1

FIG. 1 .

Kommunikation zwischen den Bienen der Bautraube zu einem "Missverständnis 》 führen kann und inwieweit ein etwa vorhandener Fehler fortgeführt wird.

Die Schwerkraft ist ein wichtiger Orientierungsparameter beim Wabenbau. Wenn Schwerkraft und $W$ abenbau in Beziehung gesetzt werden, wird meist ein positiv geotaktisches Bauen behandelt. In dieser Arbeit wurde a) das Bauverhalten der Bienen beobachtet, wenn ihnen unter verschiedenen experimentellen Bedingungen ein Bauen in entgegengesetzter Richtung ermöglicht wird (diese Versuche sind im folgenden als "Mauer-Versuche" bezeichnet) und weiterhin b) ob Jungbienen Wabenbau errichten, wenn sie niemals Kontakt mit vertikal ausgerichteten Waben hatten und ihnen dadurch die Möglichkeit fehlte, sich über die Ausrichtung der Waben und der Wabenzellen in bezug zur Schwerkraft zu orientieren.

\section{MATERIAL UND METHODE}

Die Versuche wurden im Sommer 1975 und 1976 mit Bienen der Rassen Apis mellifica carnica, mit A.m.ligustica (Nachzucht, standbegattet) und mit Heidebienen durchgeführt. Kleine Versuchsvölker (mit 
jeweils einer begatteten Königin) waren hauptsächlich in 3-Waben- und 5-Waben-Beuten aufgestellt. Die Rähmehengrösse der 3-Waben-Beuten betrug $12 \mathrm{~cm} \times 20 \mathrm{~cm}$, die der 5 -Waben-Beuten $19,5 \mathrm{~cm} \times 31 \mathrm{~cm}$.

Leitstreifen oder Mittelwände - je nach Versuch unterschiedlich geprägt - waren in die Rähmchen eingelötet. Die Leitstreifen waren je nach Versuch am Oberträger oder in der Mitte des Rahmens befestigt; handelsübliche oder auch selbst hergestellte Mittelwände fanden Verwendung.

Eine Mittelwand im Blümchenmuster wurde aus zwei Teilen gefertigt, von denen jedes eine glatte und eine im Sechseckmuster geprägte Seite hatte. Zwei solcher einseitig geprägten Wände wurden mit einem heissen Messer verschmolzen, so dass eine Seite der normalen Spitzstellung der Zellen entsprach, die andere Mittelwandseite ein um $30^{\circ}$ gedrehtes Muster aufwies (Querstellung der Zellen).

In Vorversuchen wurde die Annahme dieser aus zwei Teilen bestehenden, aber normal gemusterten Mittelwände getestet. Waren beide Mittelwandteile über die ganze Fläche gut verschmolzen, so zogen die Bienen die Zellwände der Versuchswabe genauso schnell aus wie die Zellwände einer handelsüblichen Mittelwand.

Die Versuchsvölker bestanden aus altersmässig normal zusammengesetzten Natur- oder Kunstschwärmen, ausserdem wurden Jungbienenvölker aus im Thermostaten geschlüpften Tieren verwendet.

Das Muster der Zuchtwaben war je nach Versuchsansatz unterschiedlich (Spitz-, Quer- oder Blümchenmuster). Für zwei Versuche dienten Plastikwaben mit runden Zellen als Zuchtwaben. Sie wurden aus Trovidurplatten (PVC-Material) hergestellt, in die jede Zelle einzeln gebohrt worden war; die Rückwand (=Zellgrund) bildete eine aufgeschraubte, dünne Trovidurplatte. Zellmasse der Plastikwaben : Zelldurchmesser $5,4 \mathrm{~mm}$, Zellwandstärke an dünnster Stelle $0,4 \mathrm{~mm}$, Zelltiefe $12 \mathrm{~mm}$. Das Zuchtvolk nahm diese Waben erst an, nachdem sie in flüssiges Wachs getaucht worden waren.

Die Versuche mit Jungbienenvölkern wurden beendet, sobald selbst gezogene Brut schlüpfreif war.

Die Zahl der gebotenen Rähmchen richtete sich nach Volksstärke und Bauaktivität.

Die Fütterung der Bienenvölker erfolgte zusätzlich zur natürlichen Tracht mit Pollenfutterteig und selbsthergestelltem Futterteig aus Puderzucker und Honig. Zum Herbst hin wurde ausserdem flüssig gefüttert und Wannen mit Pollen und Sojamehl aufgestellt.

Eine Nachschau jedes Versuchsvolkes erfolgte in zweitägigem Abstand, bei der die Zellen der einzelnen Wabenzungen in Höhe und Breite ausgezählt wurden.

\section{ERGEBNISSE}

In den Versuchsreihen I, II, III, IV und XI wurde untersucht, ob das Bauverhaiten der Bienen durch Lernprozesse modifiziert werden kann. Das Bauverhalten junger Bienen, die das normale Wabenmuster nie kennengelernt haben, müsste eine Aussage über starre Instinkthandlungen oder etwaige Lernmöglichkeiten zulassen. Wenn Bienen das Wabenmuster ganz oder teilweise erlernen, müsste eine Veränderung der Lerngrundlage Aufschlüsse über ererbte oder erlernte Komponenten des Bauverhaltens geben.

\section{Versuchsreihe I:}

Erlernen Bienen des Wabenmuster, aus dem sie schlüpfen und das sie belaufen?

\section{Material und Methode}

a) Versuchsansätze : Volk $1,2,3,4,5,6, \mathrm{~K}_{1}, \mathrm{~K}_{2}, \mathrm{~K}_{3}$. 
b) Versuchstiere : Jungbienen, geschlüpft aus Waben im

- Spitzmuster (Volk 1).

- Quermuster (Volk 2, 3, 4).

- Blümchenmuster (Volk 5,6).

Altersmässig normal zusammengesetzte Bienenvölker, geschlüpft aus Waben im

- Spitzmuster (Volk $\mathrm{K}_{1}, \mathrm{~K}_{2}, \mathrm{~K}_{3}$ ).

c) Volksstärke : ca. 1000 Bienen pro Volk.

d) Beutentyp : 3-Waben-Ablegerkästchen.

e) Rähmchen : ungeprägte Leitstreifen, $2 \mathrm{~cm}$ breit.

Jungbienen wurden in unterschiedlich gemusterten Waben aufgezogen. Während der Schlüpfphase und des Belaufens, Putzens und Inspizierens der Waben sollte den Bienen die Möglichkeit gegeben werden, Zellstellung und Zellgrundmuster zu erlernen. Die Bauergebnisse dieser Bienen wurden mit dem jeweiligen Zuchtwabenmuster verglichen.

Dabei wird zur besseren Veranschaulichung das Muster der gebauten Wabenzungen beschrieben. Zur genaueren Auswertung wurden die einzelnen Wabenzellen vermessen, d.h. der Neigungswinkel der Zellhauptachse zur Vertikalen wurde ermittelt (Abb. 2). Gemessen wurde jeweils der kleinste Abweichungswinkel. Durch ungleiche Kantenlängen eines Sechseckes ergeben sich Winkel von mehr als $30^{\circ}$. Bei sehr unregelmässigen Waben kommen einzelne Zellen vor, deren Hauptachse nicht der Drehtendenz der Zellreihen der Gesamtwabe folgen, sondern entgegengesetzt geneigt sind. Diese Winkelabweichungen wurden mit negativem Vorzeichen versehen.

\section{Ergebnis}

a) Bienen aus Waben mit Spitzstellung der Zellen

Volk 1

Wabe I. Spitzstellung (Abb. 3)

Wabe II. Entstanden aus 2 Zungen :

a) Spitzstellung.

b) Schrägstellung (direkt am Leitstreifen wenige Zellen in Querstellung).

Wabe III. Entstanden aus 2 Zungen :

a) Spitzstellung.

b) Schrägstellung.

Die aus Spitzmuster geschlüpften Jungbienen bauten insgesamt 2527 Zellen (Heftzellen, 5 - und 7 - eckige Zellen gehen nicht mit ein); 78,8 \% der Zellen verteilen 


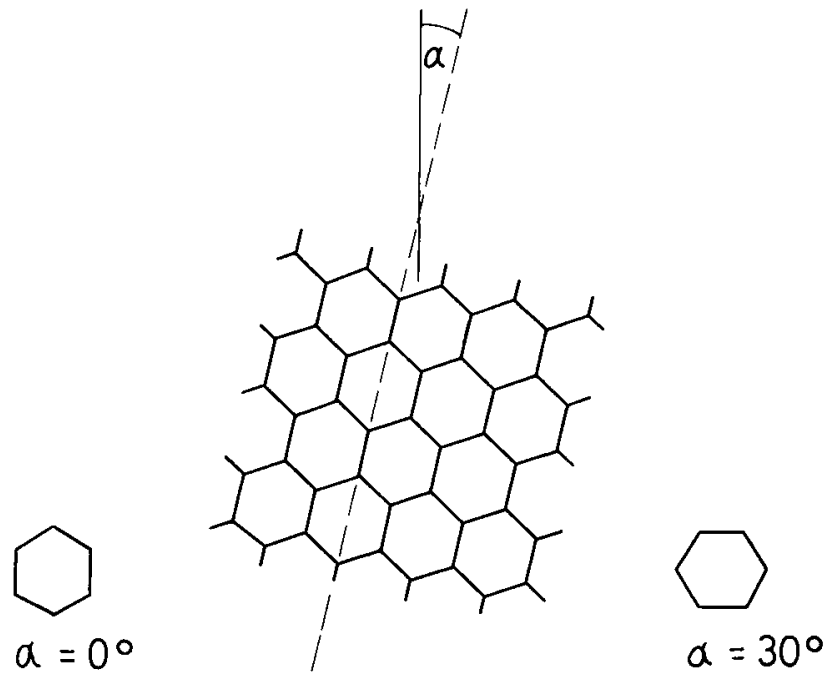

Aвв. 2

Messung der Zellstellung

$\alpha=$ Abweichungswinkel von der Vertikalen

- Z Zellhauptachse (nach LAu, 1959; verändert).

FiG. 2

Mesure de la disposition des cellules.

$\alpha=$ angle de déviation par rapport à la verticale

$--=$ axe principal de la cellule (d'après LAU, 1959; modifié).

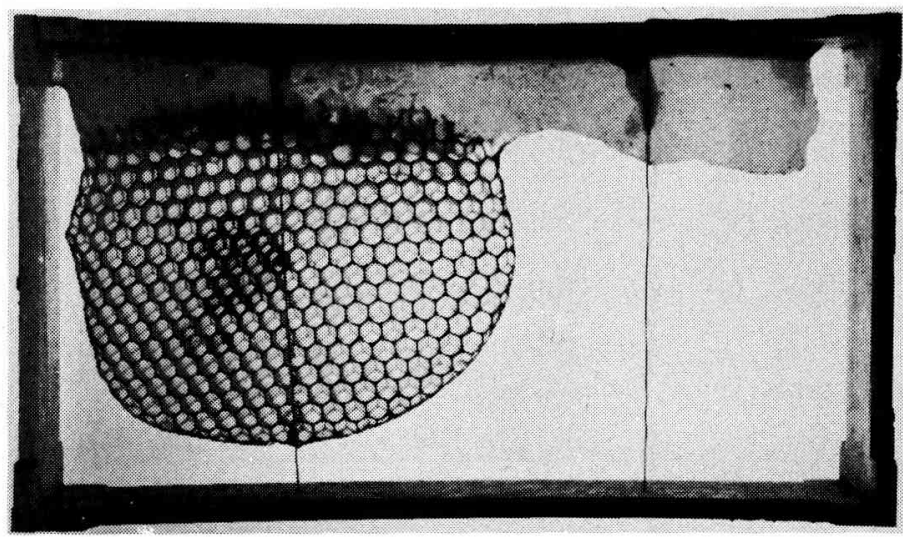

Авв. 3. - Bau am ungeprägten Leitstreifen: Spitzstellung; Volk 1.

FIG. 3. - Construction à partir d'amorces de cire sans empreinte: configuration verticale. Colonie 1. 
sich auf Abweichungswinkel von $0^{\circ}$ bis $\pm 15^{\circ}, 21,2 \%$ weisen Winkel zwischen $16^{\circ}$ und $35^{\circ}$ auf. Der Mittelwert liegt bei $10,3^{\circ}$. Die Streuung der Neigungswinkel ist erheblich (Diagramm 1). Die Zellstellung beider Seiten einer Wabe ist gleich, unregelmässige Zellgrundmuster treten nicht auf (Diagramm 2).

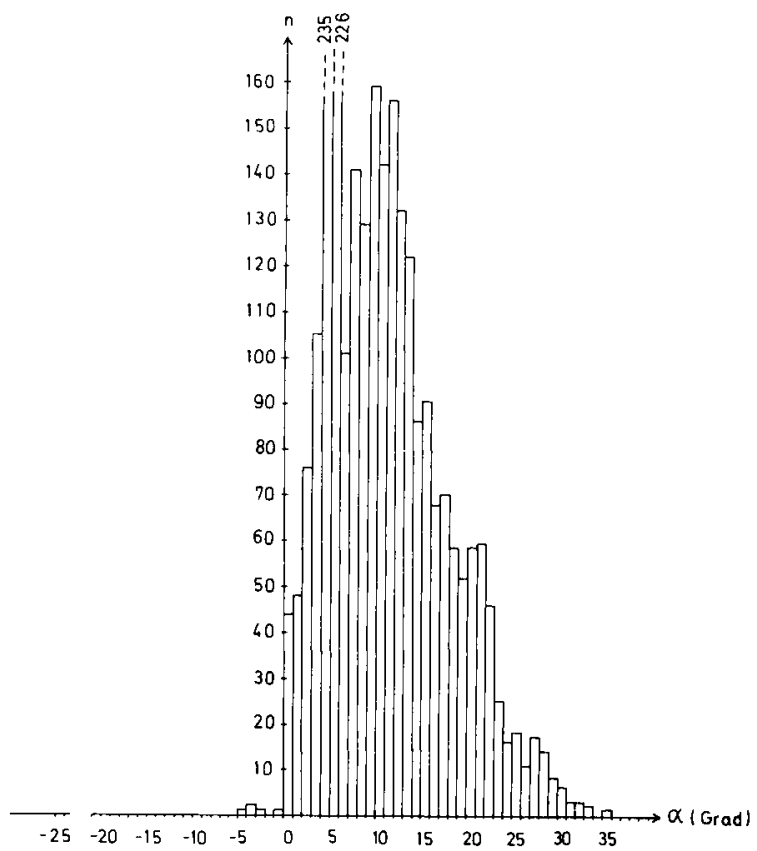

Diagramm 1. - Bauergebnisse von aus Spitzmuster geschlüpften Jungbienen (Versuchsreihe I, Volk 1): Häufigkeitsverteilung der Abweichungswinkel ( $\alpha$ ) der von ihnen gebauten Zellen. Die Werte sind normal verteilt. Das Maximum liegt bei $\alpha=4^{\circ}(n=235) ; s=6,48$.

DiAGR. 1. - Résultats de construction de jeunes abeilles nées de rayons à configuration verticale (série d'expériences I, colonie 1) : répartition de la fréquence de l'angle de déviation (a) des cellules construites par ces abeilles. Les valeurs sont réparties de façon normale. Le maximum est situé à $a=4^{\circ}$ $(n=2,35) ; s=6,48$.

b) Bienen aus Waben mit Querstellung der Zellen

Volk 2

Wabe I + II. Jeweils 13 Zellreihen gebaut : die ersten 6-9 Reihen völlig unregelmässig, die unteren 4-7 Reihen in Schrägstellung.

Volk 3

Wabe I. Spitzstellung.

Wabe II. Entstanden aus 2 Zungen :

a) Schrägstellung.

b) Querstellung. 


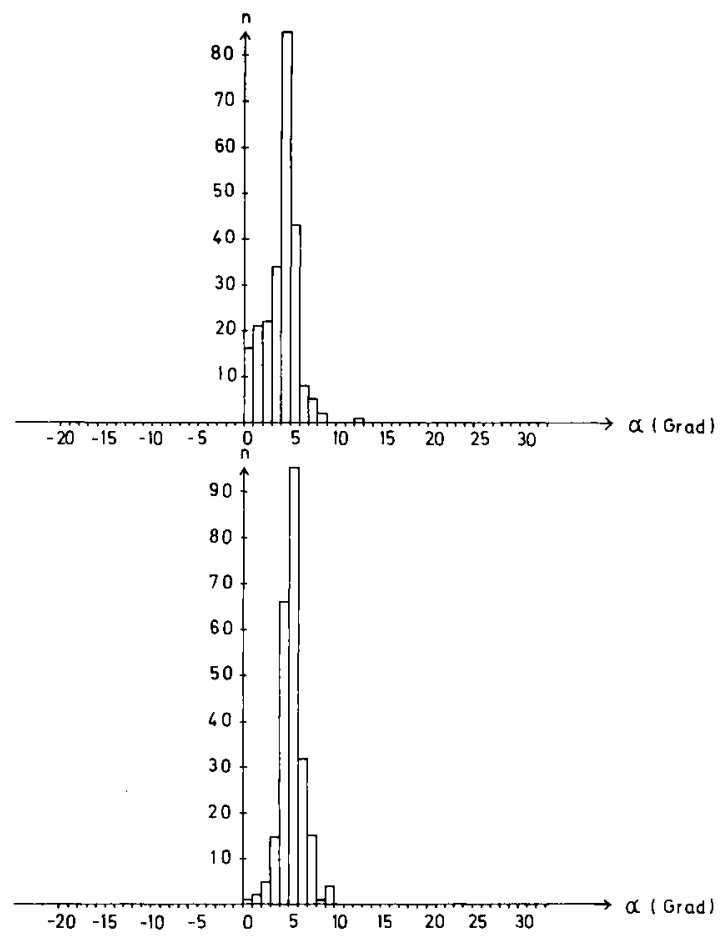

DiAGRAMM 2. - Bauergebnisse von aus Spitzmuster geschlüpften Jungbienen (Versuchsreihe I, Volk 1): Vergleich der beiden Wabenseiten einer Wabe: oben $=$ Seite 1 , unten $=$ Seite 2.

DiAGR. 2. - Résultats de construction de jeunes abeilles nées de rayons à configuration verticale (série d'expériences $I$, colonie 1$)$ : comparaison des deux faces d'un rayon : en haut $=$ face 1 ; en bas $=$ face 2 .

\section{Volk 4}

Wabe I. Bestehend aus 2 Zungen :

a) Querstellung.

b) Querstellung.

Wabe II. Bestehend aus 2 Zungen :

a) Schrägstellung.

b) Schrägstellung, am unteren Rand Drehung zu Querstellung.

Die aus Quermuster geschlüpften Bienen bauten insgesamt 1310 Zellen : 38,8 \% der Zellen zeigen Abweichungswinkel von der Vertikalen bis $15^{\circ}, 61,4 \%$ liegen zwischen $16^{\circ}$ und $36^{\circ}$. Der Mittelwert liegt bei $16,6^{\circ}$ (Diagramm 3). Die Zellstellungen jeweils beider Wabenseiten entsprechen einander, woraus sich ein regelmässiges Zellgrundmuster ergibt (Diagramm 4). 


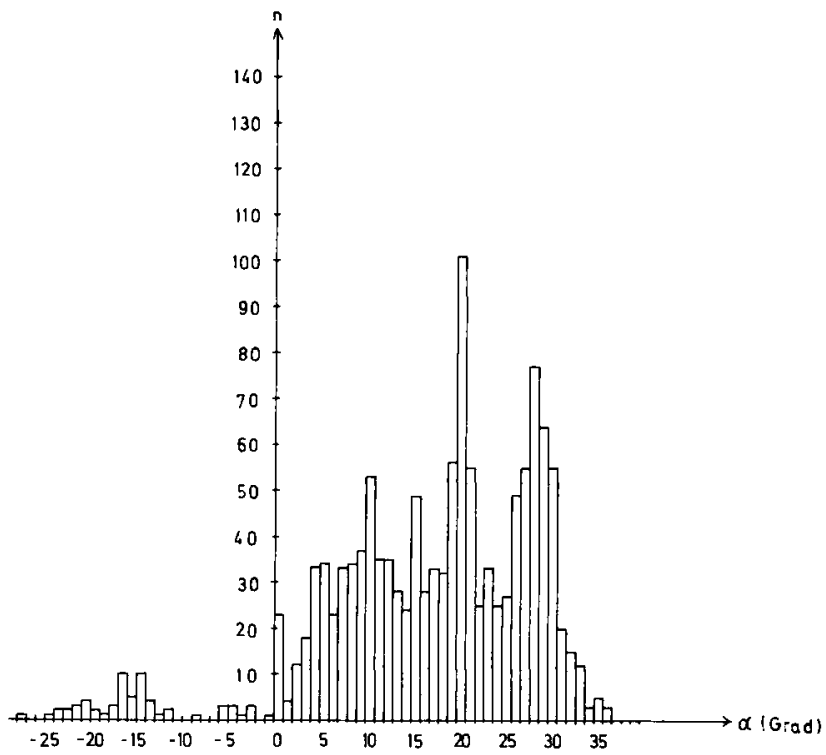

Diagramm 3. - Bauergebnisse von aus Quermuster geschlüpften Jungbienen (Versuchsreihe I, Volk 2, 3, 4) : Häufigkeitsverteilung der Abweichungswinkel $(\alpha)$ der von ihnen gebauten Zellen. Das Maximum liegt bei $\alpha=20^{\circ}(n=101) ; s=8,83$.

DIAGR. 3. - Résultats de construction de jeunes abeilles nées de rayons à configuration transversale (série d'expériences $I$, colonie 2,3 et 4 ) : répartition de la fréquence de l'angle de déviation $(\alpha)$ des cellules construites par ces abeilles. Le maximum est situé à $\left.\alpha=20^{\circ}(n=101) ; s=8,83\right)$.
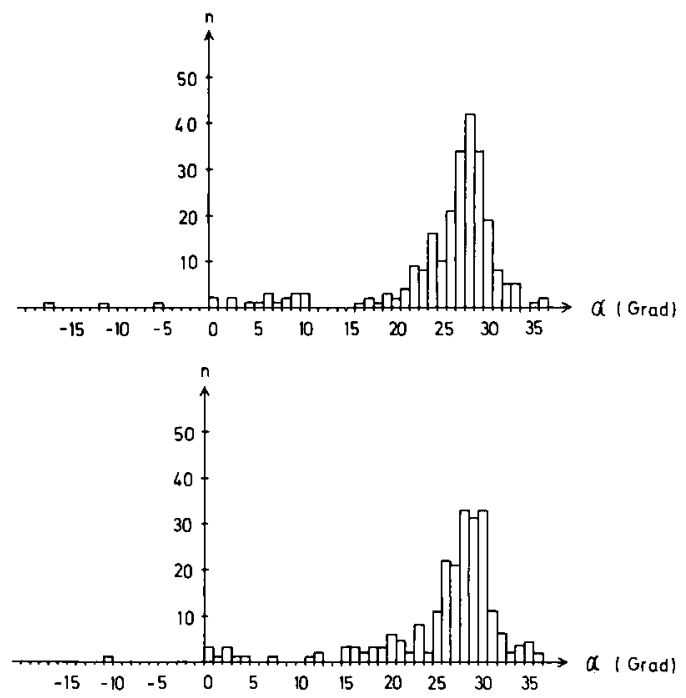

DiAgRAmM 4. - Bauergebnisse von aus Quermuster geschlüpften Jungbienen (Versuschsreihe I, Volk 4): Vergleich der beiden Wabenseiten einer Wabe: oben = Seite 1, unten = Seite 2 .

DiAGR. 4. - Résultats de construction de jeunes abeilles nées de rayons à configuration transversale (série d'expériences $I$, colonie 4) : comparaison des deux faces d'un cadre: en haut = face I; en bas = face 2. 
c) Bienen aus Waben mit Blümchenmuster

\section{Volk 5}

Wabe I. Entstanden aus 3 Zungen:

a) Blümchen, am unteren Rand Drehung zu Schrägstellung mit regelmässigem Zellgrund.

b) Spitz - und Schrägstellung, aber horizontale Verschiebung der Zellen gegeneinander.

c) Blümchen.

Wabe II. Entstanden aus 3 Zungen (Abb. 4)

a) Querstellung.

b) Spitzstellung.

c) Querstellung.

Unregelmässige Übergänge von Zunge zu Zunge, dadurch teilweise Blümchen (nicht als freie Bauzunge entstanden).

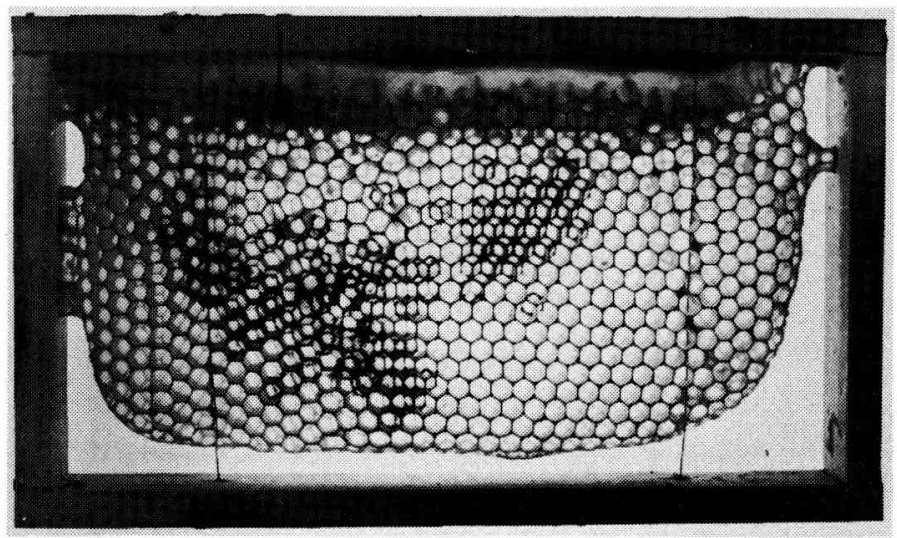

Aвв. 4. - Bau am ungeprägten Leitstreifen : Wabenabschnitt im Blümchenmuster (Pfeil); Volk 5.

FIG. 4. - Construction à partir d'amorces de cire sans empreinte: portion de rayon à configuration florale (flèche). Colonie 5.

Wabe III. Entstanden aus 2 Zungen :

a) Spitzstellung.

b) Schrägstellung.

Wabe IV. Entstanden aus 2 Zungen (Abb. 5) :

a) Spitzstellung (unsauber).

b) Blümchen.

Wabe V. Entstanden im Futterraum : Blümchen 


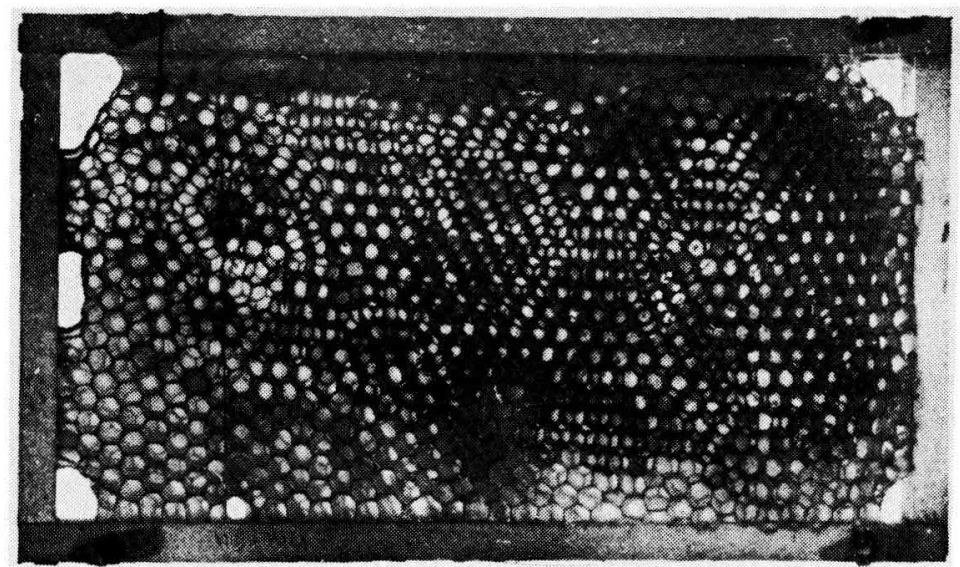

ABB. 5. - Bau am ungeprägten Leitstreifen: Linker Wabenabschnitt im Blümchenmuster (Pfeil), rechter Wabenabschnitt mit teilweise vertikal oder horizontal gegeneinander verschobenen Zellen; Volk 5.

FIG. 5. - Construction à partir d'amorces de cire sans empreinte: à gauche portion de rayon à configuration florale (flèche),

$\grave{a}$ droite portion de rayon à cellules décalées en partie verticalement ou horizontalement. Colonie 5.

\section{Volk 6}

Wabe I. Querstellung.

Wabe II. Querstellung.

Die aus Blümchenmuster geschlüpften Jungbienen bauten insgesamt 3853 Zellen.

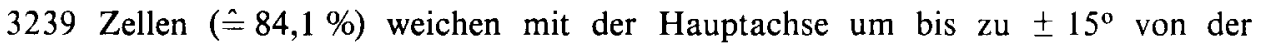
Vertikalen ab. 614 Zellen ( $\hat{=} 15,9 \%$ ) zeigen Neigungswinkel von mehr als $15^{\circ}$. Der Mittelwert aller Abweichungswinkel beträgt 6,1 ${ }^{\circ}$. Die Streuung ist gross (Diagramm 5); Zellen mit einer der Gesamtwabe entgegengesetzten Drehtendenz sind häufig (19,5\%). Die Zellstellung beider Seiten der Wabe ist nicht immer gleich (Diagramm 6; vergl. dazu Diagramm 2 und 4).

Sämtliche Bauergebnisse der Versuchsreihe I sind in Tabelle 1 zusammengestellt. Die Wabenbaumuster von Bienengruppen, die aus Waben mit unterschiedlichem Zellmuster geschlüpft waren, sind statistisch signifikant verschieden.

Die Bauergebnisse der Kontrollvölker $\left(\mathrm{K}_{1}, \mathrm{~K}_{2}, \mathrm{~K}_{3}\right)$ schiiessen jahreszeitliche und standortbedingte Abweichungen von der normalen Zellstellung aus.

\section{II. - Versuchsreihe II :}

Bauergebnisse von Bienen, die keinen Kontakt mit sechseckigen Wabenmustern hatten

\section{Material und Methode}

a) Versuchsansätze : Volk 1. 


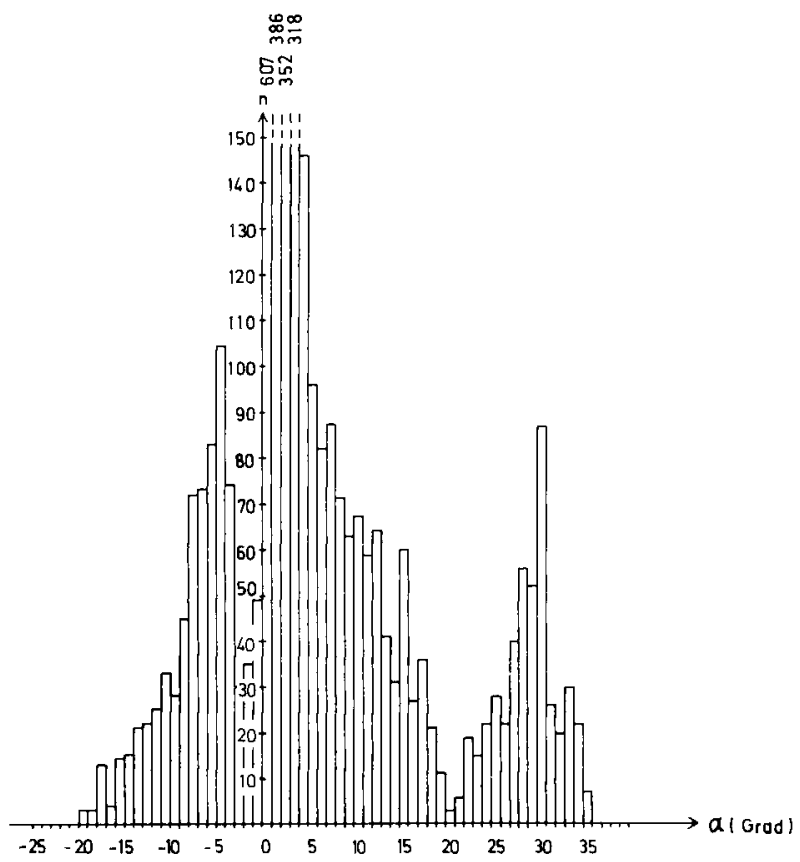

DiAGRAMM 5. - Bauergebnisse von aus Blümchenmuster geschlüpften Jungbienen (Versuchsreihe I, Volk 5, 6): Häufigkeitsverteilung der Abweichungswinkel $(\alpha)$ der von ihnen gebauten Zellen. Das Diagramm zeigt 3 Gipfel. Der grösste ermittelte Wert liegt bei $\alpha=0^{\circ}(n=607)$. Links des Hauptgipfels liegt ein weiterer Extremwert bei $\alpha=-5^{\circ}(n=104)$, zwischen $a=-4^{\circ}$ und $\left(\mathrm{\imath}=20^{\circ}\right.$ finden sich $16,8 \%$ der Zellen $(n=647)$. Der dritte Extremwert liegt bei $\gamma=30^{\circ}(n=87) ; 11,8 \%$ $(n=453)$ der Zellen verteilen sich zwischen $\alpha=20^{\circ}$ und $\alpha=35^{\circ}$.

DIAGR. 5. - Résultats de construction de jeunes abeilles nées de rayons à configuration florale (série d'expériences $I$, colonies 5,6$)$ : répartition de la fréquence de l'angle de déviation ( $(x)$ des cellules construites par ces abeilles. Le diagramme montre 3 sommets. La valeur moyenne la plus élevée est $\alpha=0^{\circ}$ $(n=607)$. A gauche du sommet principal une autre valeur extrême est située à $\alpha=-5^{\circ}(n=104)$; entre $\alpha=-4^{\circ}$ et $\alpha=20^{\circ}$ se trouvent $16,8 \%$ des cellules $(n=647)$. La $3^{\mathrm{e}}$ valeur extrême est $\alpha=30^{\circ}$ $(n=87) ; 11,8 \%(n=453)$ des cellules sont situées entre $\alpha=20^{\circ}$ et $\alpha=35^{\circ}$.

b) Versuchstiere : Jungbienen, geschlüpft aus Plastikwaben mit runden Zellen.

c) Volksstärke : ca. $600-800$ Bienen.

d) Beutentyp : EWK.

e) Rähmchen : ungeprägter Leitstreifen, $2 \mathrm{~cm}$ breit.

Diese, aus Plastikwaben mit runden Zellen geschlüpften Tiere beliefen, putzten und inspizierten nur diesen Wabentyp. Sie hatten keinen Kontakt mit sechseckigen Wabenmustern.

2. Ergebnis

Volk 1

Wabe I. Entstanden aus 2 Zungen (am Leitstreifen) :

a) Blümchen.

b) Anfangs Spitzstellung, dann zu Querstellung gedreht. 


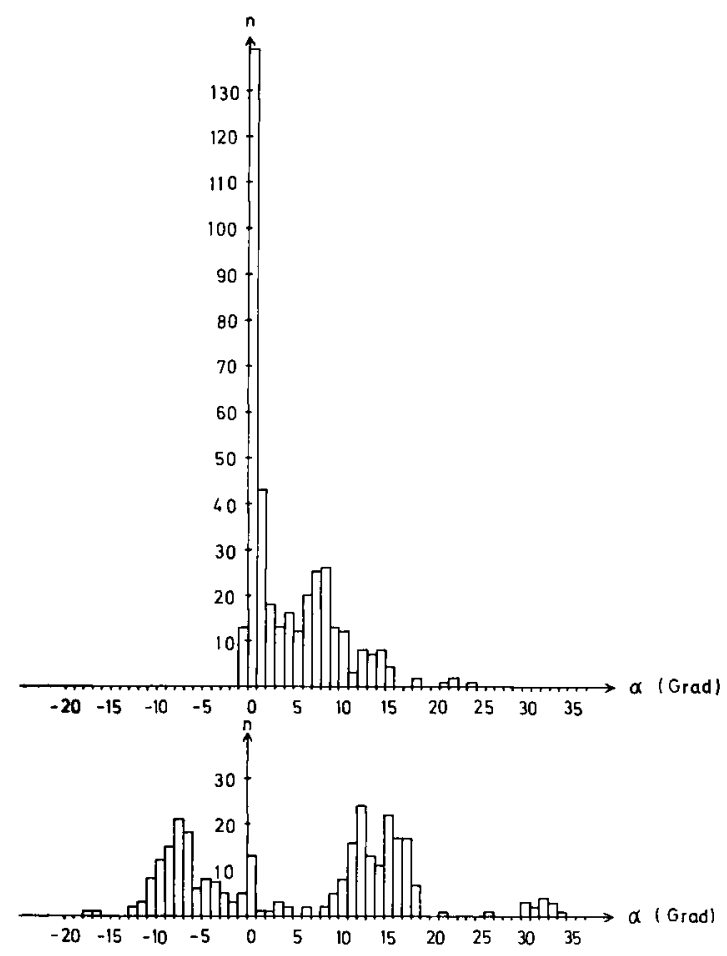

DIAGRAMM 6. - Bauergebnisse von aus Blümchenmuster geschlüpften Jungbienen (Versuchsreihe I, Volk 5) : Vergleich der beiden Wabenseiten einer Wabe: oben = Seite 1, unten = Seite 2.

DIAGR. 6. - Résultats de construction de jeunes abeilles nées de rayons à configuration florale (série d'expériences 1 , colonie 5): comparaison des 2 faces d'un rayon; en haut : face 1 : en bas $=$ face 2.

Sechs kleine Wabenzungen entstanden im Futterraum :

Zunge I. Querstellung (ungenau).

Zunge II. Spitzstellung (einschichtiges Wabenstück).

Zunge III. Unregelmässiger Bau (ein Blümchenmuster).

Zunge IV. Schrägstellung.

Zunge V. Spitz- und Schrägstellung.

Zunge VI. Blümchen.

Die aus runden Zellen geschlüpften Jungbienen bauten insgesamt 441 Zellen (Heftzellen, 4-, 5- und 7- eckige Zellen ausgenommen). Die gemessenen Abweichungswinkel der Zellhauptachse von der Vertikalen sind in Diagramm 7 aufgetragen. Die Streuung ist gross. $12 \%$ der Zellen folgen nicht der Drehtendenz der Zellreihen. Maxima treten bei $0^{\circ}, 10^{\circ}$ und $25^{\circ}$ auf (Tabelle 3).

Bienen, die aus runden Zellen geschlüpft sind und auch nur diese Zellform kennengelernt hatten, bauten sechseckige Zellen. Aber es traten grosse 
TAB. 1. - Statistische Bewertung der Bauergebnisse aus der Versuchsreihe 1. Mediantest aus SaCHS, 1974. Für die Bauergebnisse der aus Blümchenmuster geschlüpften Bienen wurde das arithmetische Mittel $(\hat{x})$ und die Standardabweichung $(s)$ angegeben, obwohl wir davon ausgehen können, dass hier keine Normalverteilung vorliegt (mehrgipflig).

TABL. 1. - Évaluation statistique des résultats de construction de la série d'expériences $n^{\circ} 2$. Test de moyenne de SACHs. 1974. Pour les résultats de construction des abeilles écloses de rayons en plastique on a donné la moyenne arithmétrique $(\bar{x})$ et l'écart-type $(s)$, bien que nous puissions en dèduire qu'il n'existe aucune distribution normale (polymodale).

\begin{tabular}{|c|c|c|c|c|c|c|}
\hline \multirow{2}{*}{$\begin{array}{c}\text { Geschlüpft aus } \\
\text { Éclos de rayons } \\
\text { à configuration }\end{array}$} & \multirow{2}{*}{$n$} & \multicolumn{2}{|c|}{$\begin{array}{l}\text { Abweichung von der Lotrechten } \\
\text { Déviation par rapport à la verticale }\end{array}$} & \multirow{2}{*}{$\begin{array}{c}\text { Mittelwert } \\
\text { Moyenne } \\
\dot{x}\end{array}$} & \multirow{2}{*}{$s$} & \multirow{2}{*}{$\begin{array}{l}\text { Mediantest } \\
\text { Test de moyenne }\end{array}$} \\
\hline & & $\begin{array}{l}<15^{\circ} \\
\text { in } \%\end{array}$ & $\begin{array}{l}>15^{\circ} \\
\text { in } \%\end{array}$ & & & \\
\hline $\begin{array}{l}\text { Spitzmuster } \\
\text { Verticale }\end{array}$ & 2527 & 78,8 & 21,2 & $10,3^{\circ}$ & $6,48^{\circ}$ & \multirow{2}{*}{$\begin{array}{c}\text { Spitzm./Querm } \\
\begin{array}{c}\text { Conf. verticale } \\
\text { /transversale }\end{array} \\
x^{\cdot 2}=54,84 \\
P<0,001\end{array}$} \\
\hline $\begin{array}{l}\text { Quermuster } \\
\text { Transversale }\end{array}$ & 1310 & 38,8 & 61,2 & $16,6^{\circ}$ & $8,83^{\circ}$ & \\
\hline $\begin{array}{l}\text { Blümchenmuster } \\
\text { Florale }\end{array}$ & 3853 & 84,1 & 15,9 & $6,1^{\circ}$ & $11,02^{\circ}$ & $\begin{array}{c}\text { Spitzm./Blüm. } \\
\text { Conf. } \\
\text { verticale/florale } \\
x^{.2}=137,22 \\
P<0,001\end{array}$ \\
\hline
\end{tabular}

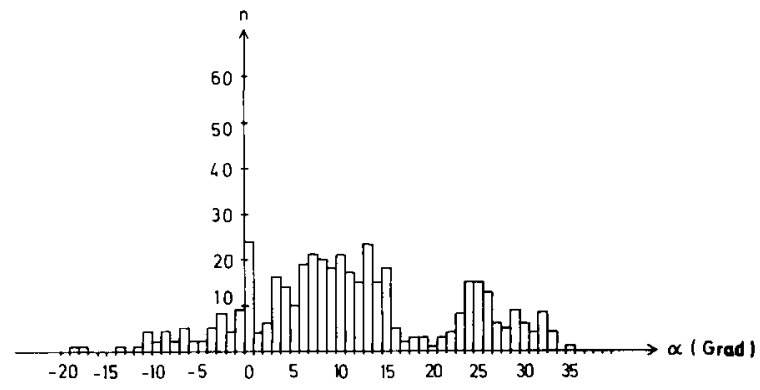

DiAgRAmm 7. - Bauergebnisse von aus Plastikwaben mit runden Zellen geschlüpften Jungbienen (Versuchsreihe II, Volk 1) : Häufigkeitsverteilung der Abweichungswinkel $(\alpha)$ der von ihnen gebauten Zellen. Die Verteilungs-Kurve verläuft flach. Ein vergleichbares Maximum wie in Diagramm 1 tritt nicht auf.

DIAGR. 7. - Résultats de construction de jeunes abeilles nées de rayons en plastique à cellules rondes (série d'expériences 2, colonie 1): répartition de la fréquence de l'angle de déviation ( $(\boldsymbol{V})$ des cellules construites par ces ubeilles. La courbe de réparation est plate. Il n'y a pas de maximum comparable à celui du diagramme $I$. 
TAB. 2. - Bauergebnisse der Völker 2, 3 und 4 (geschlüpft aus Zuchtwaben im Quermuster): Beziehung zwischen der Winkelabweichung und dem Zeitpunkt des Baubeginns.

TABL. 2. - Résultats de construction des colonies 2, 3 et 4 (écloses de rayons à configuration transversale):

relation entre l'angle de déviation et la date de début de construction.

\begin{tabular}{c|l|c|c|c}
\hline Volk & $\begin{array}{l}\text { Baubeginn nach dem Aufstellen in Tagen } \\
\text { Début de la construction apres l'installation (en } \\
\text { jours) }\end{array}$ & $n$ & $\begin{array}{l}\bar{x} \text { der Abweichungswinkel von der } \\
\text { Vertikalen } \\
\text { Moyenne de l'angle de déviation par rapport à } \\
\text { la verticale }\end{array}$ \\
\hline 2 & 6 & 181 & $10,1^{\circ}$ \\
3 & 5 & 101 & $13,6^{\circ}$ \\
4 & 3 & 1023 & $18,1^{\circ}$ \\
\hline \hline
\end{tabular}

TAB. 3. - Statistische Bewertung der Bauergebnisse aus der Versuchsreihe 1I. Mediantest aus SACHS, 1974. Für die Bauergebnisse der aus Plastikwaben geschlüpften Bienen wurde das arithmetische Mittel $(\bar{x})$ und die Standardabweichung $(s)$ angegeben, obwohl wir davon ausgehen können, dass hier keine Normalverteilung vorliegt (mehrgipflig).

TABL. 3. - Évaluation statistique des résultats de construction de la série d'expériences $n^{\circ} 2$. Test de moyenne de SACHs, 1974. Pour les résultats de construction des abeilles écloses de rayons en plastique, on a donné la moyenne arithmétique $(x)$ et l'écart-type $(s)$, bien que nous puissions en déduire qu'il n'existe aucune distribution normale (polymodale).

\begin{tabular}{l|c|c|c|l}
\hline \hline Geschlüpft & $n$ & $\begin{array}{c}\text { Mittelwert } \\
x\end{array}$ & $s$ & Mediantest \\
Éclos de rayons & 2527 & $10,3^{\circ}$ & $6,48^{\circ}$ & $\begin{array}{l}\text { Spitzmuster/Plastikwaben (runde Zellen) } \\
\text { Configuration verticale/rayons en plastique (cel- } \\
\text { lules rondes) } \\
\text { Spitzmuster }\end{array}$ \\
$\begin{array}{l}\text { à configuration verticale } \\
\begin{array}{l}\text { Plastikwaben (rundeZellen) } \\
\text { en plastique (cellules } \\
\text { rondes) }\end{array}\end{array}$ & 441 \\
\hline \hline
\end{tabular}

Unregelmässigkeiten in Zellform und Zellgrösse, sowie sämtliche Zellmuster nebeneinander auf.

III. - Versuchsreihe III :

Erlernen Bienen Wabenmuster beim Ausbau?

1. Material und Methode

a) Versuchsansätze : Volk 1, 2, K

b) Versuchstiere : Jungbienen wurden, als sie den Zelldeckel aufzunagen begannen, mit einer Pinzette aus der Zelle befreit und damit der Kontakt des adulten Tieres mit einer normal gemusterten Wabe 
ausgeschlossen (Volk 1,2). Aus Spitzmusterzuchtwaben geschlüpfte Tiere; normale Alterszusammensetzung (Volk K).

c) Volksstärke : ca. 1000 Bienen pro Volk.

d) Beutentyp : 3-Waben-Ablegerkästchen.

e) Rähmchen : Volk 1 erhielt nacheinander

$a$. Blümchenmustermittelwände.

$b$. Blümchenmusterleitstreifen, $2 \mathrm{~cm}$ breit.

c. ungeprägte Leitstreifen, $2 \mathrm{~cm}$ breit.

Volk 2 und $\mathrm{K}$

$a$. Spitzmustermittelwände.

$b$. Spitzmusterleitstreifen, $2 \mathrm{~cm}$ breit.

c. ungeprägte Leitstreifen, $2 \mathrm{~cm}$ breit.

Die aus den Zellen befreiten Tiere waren weniger vital als normal geschlüpfte, gleichaltrige Individuen. Der Totenfall war stark erhöht, und es dauerte lange, bis ein Volksverband entstand. Die Tiere zeigten verfrühte positive Phototaxis (VollBeHR, 1975), was dazu führte, dass ein Teil der Versuchsbienen aus den Fluglöchern herauslief und - da sie noch flugunfähig waren - nicht selbständig zum Volk zurückkehrte.

Bei der Auswertung des Baumusters wurde nur berücksichtigt, ob Blümchenmuster oder Normalmuster auftrat; auf ein genaues Ausmessen der Winkelabweichungen konnte verzichtet werden.

2. Ergebnis

a) Vorgabe von Mittelwänden

Volk 1 : Blümchen.

Volk 2 : Spitzstellung.

Volk K : Spitzstellung.

Die Bauergebnisse entsprachen dem jeweils vorgegebenen Muster.

b) Vorgabe von geprägten Leitstreifen

Volk 1 : Blümchen (Abb. 6).

Volk 2 : Spitzstellung.

Volk K : Spitzstellung.

Die Bauergebnisse entsprachen dem jeweils vorgegebenen Muster.

c) Vorgabe von ungeprägten Leitstreifen

Volk 1:

Wabe I. Spitzstellung.

Wabe II. Querstellung, am unteren Rand zu Schrägstellung gedreht.

\section{Volk 2:}

Wabe I. Spitzstellung.

Wabe II. Querstellung. 


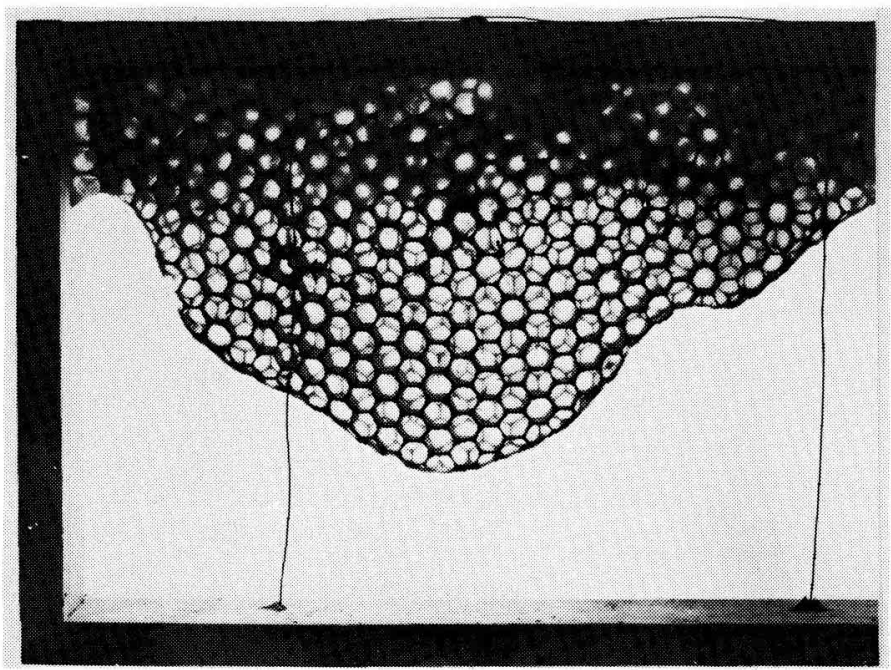

ABB. 6. - Ausgebauter Blümchenmuster-Leitstreifen; Volk 1.

FIG. 6. - Amorces de cire construites avec la configuration florale. Colonie 1.

Volk K :

Wabe I. Spitzstellung.

Wabe II. Schrägstellung.

Die Zellgrundverzahnung ist regelmässig, Blümchenmuster wurde nicht gebaut.

IV. - Versuchsreihe IV:

Anpassung an gegebene Bausituationen

\section{Material und Methode}

a) Versuchsansätze : Volk 1, 2, 3, 4, 5, 6, 7, 8

b) Versuchstiere : Jungbienen, geschlüpft aus Waben im

- Spitzmuster (Volk 1-4).

- Blümchenmuster (Volk 5-8).

c) Volksstärke : 800-1000 Bienen pro Volk.

d) Beutentyp : 3-Waben-Ablegerkästchen.

e) Rähmchen : Leitstreifen

- im Spitzmuster (Volk 1, 5)

- im Blümchenmuster (Volk 2, 3, 6, 7)

- ungeprägt (Volk 4, 8).

Innerhalb eines grossen Volkes schlüpfen Bienen unter Umständen aus verschiedenen Wabenmustern. Können sie sich vorhandenen Bausituationen anpassen, 
um zu einer Einheitlichkeit zu gelangen? Die Reaktion von Jungbienen (geschlüpft aus Spitzstellung oder Blümchenmuster) auf vorgegebene unterschiedliche Bausituationen wurde geprüft.

\section{Ergebnis}

a) Vorgabe von Spitzmusterleitstreifen

\section{Volk 1:}

Wabe I. Spitzstellung.

Volk 5:

Wabe I. Spitzstellung.

b) Vorgabe von Blümchenmusterleitstreifen.

Volk 2:

Wabe I. Blümchen.

\section{Volk 3:}

Wabe I. Blümchen (Abb. 7).

Wabe II. Blümchen.

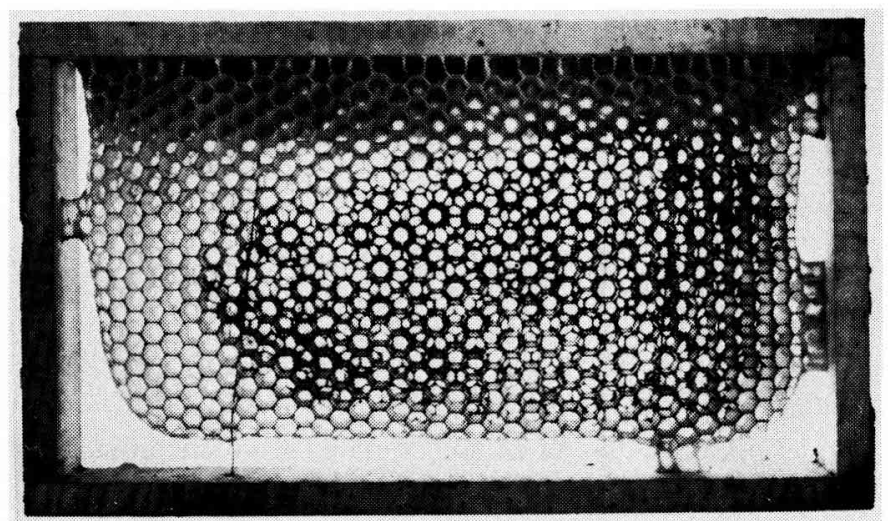

AвB. 7. - Ausgebauter Blümchenmuster-Leitstreifen: Volk 3.

FIG. 7. - Amorces de cire construites avec la configuration florale. Colonic 3.

Volk 6:

Wabe I. Blümchen, am unteren Rand der Zunge zu Spitzstellung verändert.

\section{Volk 7 :}

Wabe I. Blümchen.

Wabe II. Blümchen, am unteren Rand der Wabe einige Zellen in Querstellung. 
c) Vorgabe von ungeprägten Leitstreifen

Volk 4 :

Wabe I. Nur wenige Zellen gebaut, Spitzstellung.

Volk 8 :

Wabe I. Kleine Zunge, unregelmässiger Bau mit einem glatten Zellgrund (Blümchen), am Rand der Wabenzunge zu Querstellung gedreht.

Die Bauergebnisse der beiden, aus unterschiedlichen Mustern geschlüpften Bienengruppen entsprechen prinzipiell dem vorgegebenen Leitstreifenmuster; am ungeprägten Leitstreifen unterscheiden sich die Ergebnisse.

\section{V. - Versuchsreihe $V$ :}

Bauergebnisse am $6 \mathrm{~mm}$ breiten Blümchenmusterleitstreifen

1. Material und Methode

a) Versuchsansätze : Volk 1,2, 3.

b) Versuchstiere : Jungbienen, geschlüpft aus Waben im Spitzmuster.

c) Volksstärke : ca. 1000 Bienen pro Volk.

d) Beutentyp : 3-Waben-Ablegerkästchen.

e) Rähmchen : Leitstreifen im Blümchenmuster, $6 \mathrm{~mm}$ breit.

Diese Versuchsreihe soll lediglich aufzeigen, ob ein vorgegebenes Wabenmuster von nur einer Zellreihe mustergerecht weitergeführt wird.

2. Ergebnis

Volk 1 : Schrägstellung.

Volk 2 : Querstellung.

Volk 3 : Einige Zellreihen Blümchen, dann gedreht zu Querstellung.

Zwei der drei Völker bauten einen so schmalen Blümchenmusterleitstreifen nicht im vorgegebenen Muster weiter.

VI. - Versuchsreihe VI:

Ausbau von Blümchenmusterleitstreifen durch altersmässig normal zusammengesetzte Völker

\section{Material und Methode}

a) Versuchsansätze : Volk 1, 2, 3, 4

b) Versuchstiere : Kunstschwärme. 
c) Volksstärke : 1200-1400 Bienen pro Volk.

d) Beutentyp : 3-Waben-Ablegerkästchen.

e) Rähmchen : Mittelwände bzw. Leitstreifen unterschiedlicher Breite im Blümchenmuster; Anzahl der Rähmchen je nach Bauaktivität.

f) Versuchszeit : Juli-September (Volk 1, 2).

Ende August-September (Volk 3, 4).

Bei der Auswertung der Bauergebnisse wurde nur berücksichtigt, ob Blümchenmuster oder Normalmuster auftrat; auf ein genaues Ausmessen der Winkelabweichungen konnte verzichtet werden.

\section{Ergebnis}

a) Vorgabe von Blümchenmustermittelwänden.

Volk 1: Blümchen.

Volk 2: Blümchen.

b) Vorgabe von Blümchenmusterleitstreifen

Leitstreifen $2 \mathrm{~cm}$ breit (ca. 4 Zellreihen)

\section{Volk 1:}

Wabe I. Blümchen.

Volk 2:

Wabe I. Übergang zu Spitzstellung unterhalb des Leitstreifens.

Wabe II. Entstanden aus 2 Zungen (Abb. 8)

a) Blümchen.

b) Spitzstellung.

Leitstreifen $4 \mathrm{~cm}$ breit (ca. 8 Zellreihen).

Volk 3 :

Wabe I. Unregelmässige Blümchen, etwas Spitzstellung

Wabe II. Blümchen (Wabe wenig über den Leitstreifen hinausgebaut).

Wabe I. Blümchen.

Volk 4 :

Wabe II. Blümchen, im unteren Bereich etwas Spitzstellung.

Leitstreifen $1,1 \mathrm{~cm}$ breit (2 Zellreihen)

Volk 4 :

Wabe I. Blümchen, dann Drehung zu Querstellung mit regelmässigem Zellgrund. 


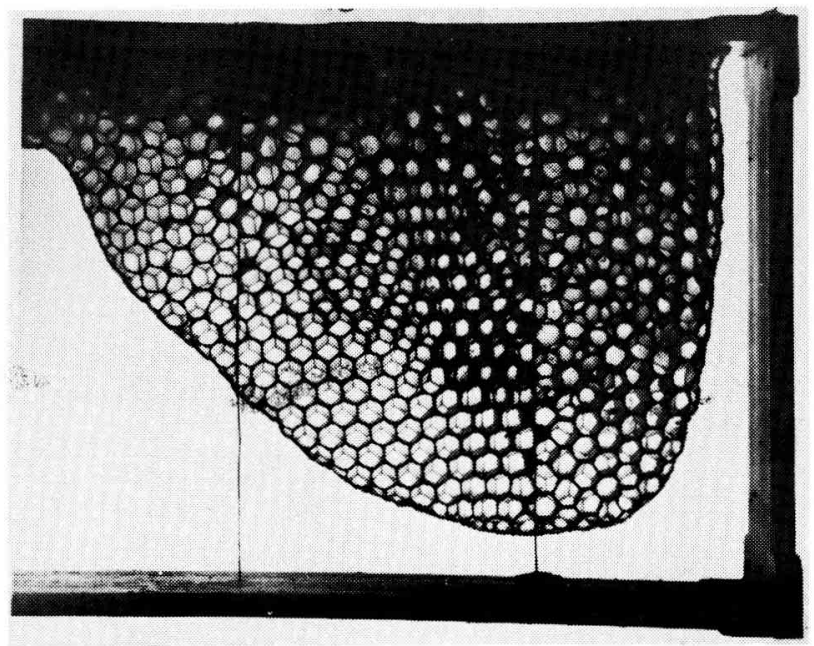

Aвв. 8. - Bau am Blümchenmuster-Leitstreifen: Teilweise Veränderung zu Normalmuster; Volk 2.

FIG. 8. - Construction à partir d'amorces de cire à configuration florale: modification partielle vers la configuration normale. Colonie 2.

Wabe II. Entstanden aus 2 Zungen

a) Blümchen.

b) Querstellung.

Die Bauergebnisse zeigen weder eine Abhängigkeit von der Breite der Leitstreifen (ca. 1-4 cm) noch von der Häufigkeit des Ausbaues des Blümchenmusters.

VII. - Versuchsreihe VII :

Ausbau von Blümchenmusterleitstreifen in Abhängigkeit von Jahreszeit und Volksst Volksstärke

1. Material und Methode

a) Versuchsansätze : Volk 1, 2, 3, 4.

b) Versuchstiere : Kunstschwärme.

c) Volksstärke : ca. 800 Bienen (Volk 1 u. 2).

ca. 1300 Bienen (Volk 3 u. 4).

d) Beutentyp : 3-Waben-Ablegerkästchen.

e) Rähmchen : 2 Zellreihen breite Blümchenmusterleitstreifen (Versuchreihe VI zeigte, dass das Blümchenmuster bei dieser geringen Breite weitergeführt wird). 
2. Ergebnis

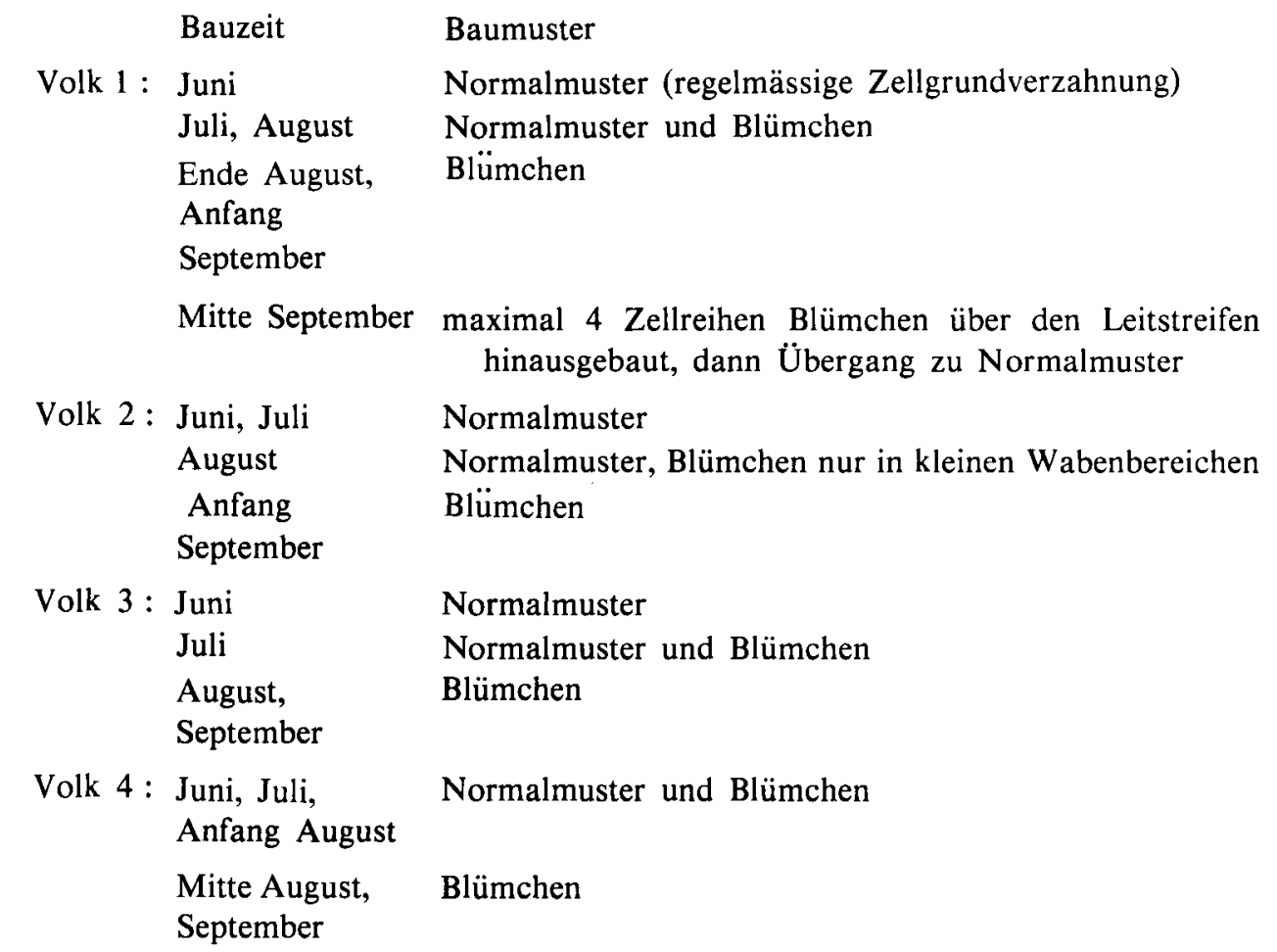

Der Ausbau des Blümchenmusters ist abhängig von der Jahreszeit und nicht von der Volksstärke.

\section{VIII. - Versuchsreihe VIII : \\ Versuch zur Trennung der Bautraube}

1. Material und Methode

a) Versuchsansätze : Volk 1 .

b) Versuchstiere : Naturschwarm.

c) Volksstärke : ca. 15000 Bienen.

d) Beutentyp : Strohkorb mit einem abnehmbaren, flachen Deckel.

e) Rähmchen : U-förmiger Rahmen $(25 \mathrm{~cm}$ Höhe $\times 27,5 \mathrm{~cm}$ Breite $)$ mit Planktongaze bespannt; Blümchenmusterleitstreifen $(4,5 \mathrm{~cm}$ Höhe $\times 19 \mathrm{~cm}$ Breite), dessen Hälften durch die Gaze geteilt wurden.

Die Bienen hatten durch ein Absperrgitter freien Zugang zur Königin, die über dem Oberträger gekäfigt war. Der Schwarm wurde beim Einschlagen gleichmässig auf beiden Seiten der Gaze verteilt. Der freie Teil der Gaze wurde nachträglich bewachst. 
Bei diesem Versuch sollte ein Seitenwechsel der Baubienen innerhalb der Bautraube durch die Gaze eingeschränkt und das Bauverhalten beobachtet werden, wenn eine Kommunikation über die Anlage des Zellbodens erschwert bzw. unterbunden ist.

Die Bienen bauten langsam und auf den beiden Seiten des Versuchsrahmens unterschiedlich viel.

\section{Ergebnis}

a) Seite $\mathrm{A}$ des Blümchenmuster-Leitstreifens (Spitzstellung)

Es wurde kaum über den vorgegebenen Leitstreifen hinausgebaut. Der Zellgrund des Streifens ist dick, an einigen Stellen aber bis auf die Gaze abgenagt. Nur am unteren Rand des Leitstreifens wurden wenige Zellwände auf die Gaze gesetzt. Ein Zellgrund fehlt, die Zellgrösse der neuen sechseckigen Zellen erscheint gleichmässig.

b) Seite B des Blümchenmuster-Leitstreifens (Querstellung)

Die über den Zellstreifen hinausgebauten Zellwände sind dünnwandig, die Zellgrösse gleichmässig. Ein richtiger Zellgrund fehlt; auch auf dieser Seite bildet die Gaze den Zellgrund der neu angesetzten Zellwände.

Die Zellwände, die auf die Gaze gesetzt wurden, schliessen nicht mit der Gegenseite in gleicher Höhe ab.

Bienen bauen das normale Sechseckmuster auch dann regelmässig weiter, wenn sie keinen normalen Zellboden zur Verfügung haben und am Rand der Bautraube der Kontakt gestört ist.

$$
\text { IX. - Versuchsreihe IX: }
$$

Mustergebende Elemente der Wabenzelle

\section{Material und Methode}

a) Versuchsansätze : Volk $1,2$.

b) Versuchstiere Jungbienen, geschlüpft aus Waben mit Spitzstellung der Zellen.

c) Volkstärke : ca. 1000 Bienen pro Volk.

d) Beutentyp : 3-Waben-Ablegerkästchen.

e) Rähmchen : Leitstreifen aus einer $7 \mathrm{~cm}$ breiten, einseitig geprägten Wachswand (Spitz- oder Quermuster), auf die vom oberen Rand aus auf der glatten Seite ein $3 \mathrm{~cm}$ breiter, einseitig geprägter Wachsstreifen, im Muster um $30^{\circ}$ verdreht, aufgebracht worden war. 
Beim Ausbau dieser Leitstreifen wurde von den Bienen die Entscheidung zwischen einer bestimmten Zellstellung und einem regelmässig gemusterten, aber nicht zur vorgegebenen Zellstellung gehörenden Zellgrund verlangt. Es sollte geklärt werden, welche Elemente der Wabenzelle für Bienen mustergebend sind.

\section{Ergebnis}

Volk 1 und 2:

Die Bienen bauten über den kurzen Streifen hinaus entsprechend der Zellstellung. Zellwände dieser Zellstellung wurden auf die glatte Rückwand des langen Streifens aufgesetzt. Die so entstandenen Zellen hatten einen glatten, unnatürlich dicken Zellgrund, der beim weiteren Ausbau auf Normalstärke abgenagt wurde. Im weiteren Bauverlauf drehten die Bienen unterhalb des kurzen Leitstreifens die Zellstellung um ca. $30^{\circ}$, so dass ein regelmässiges Zellgrundmuster entstand. Volk 1 und 2 bauten schliesslich alle Waben gemäss dem Zellgrundmuster des langen Leitstreifens aus.

Der Bau von Zellwänden auf glatter Wachswand geschah folgendermassen : Nacheinander wurden die Zellwände gebaut, die sich zum Sechseck schlossen. Die Anlage der Wabenzellen erfolgte sofort in Sechseckform; allerdings wurde nie beobachtet, dass Zellwände im Winkel von $120^{\circ}$ angelegt wurden, ohne dass im Scheitelpunkt eine weitere Zellwand ansetzte.

\section{X. - Versuchsreihe $X$ : \\ Mauer-Versuche}

1. Material und Methode
a) Versuchsansätze : Volk 1, 2, 3, 4 .
b) Versuchstiere : Kunstschwarm (Volk 1). Naturschwarm (Volk 2, 3, 4).
c) Volksstärke : ca. 1300 Bienen (Volk 1).
ca. 10000 Bienen (Volk 2).
ca. 8000 Bienen (Volk 3).
ca. 15000 Bienen (Volk 4).
d) Beutentyp : 3-Waben-Ablegerkästchen (Volk 1).
5-Waben-Ableger (Volk 2, 3, 4).

e) Rähmchen : Blümchenmuster-Leitstreifen von $2 \mathrm{~cm}$ Breite; Zwischenraum Oberkante Leitstreifen/Oberträger : $4 \mathrm{~cm}$ (Volk 1); Leitstreifen im Normalmuster von $3,5 \mathrm{~cm}$ Breite; Zwischenraum Oberkante Leitstreifen/Oberträger : $7,5 \mathrm{~cm}-12 \mathrm{~cm}$ (Volk 2, 3, 4).

Das Bauverhalten der Bienen wurde beobachtet, wenn ein Bauen in entgegengesetzter Richtung, also von unten nach oben, ermöglicht wird. Da das 
Entstehen einer Wabe auf diese Art an das "Mauern einer Wand " erinnert, werden diese Versuche als "Mauer-Versuche » bezeichnet.

\section{Ergebnis}

a) Vorgabe von Leitstreifen im Blümchenmuster.

\section{Volk 1 (Abstand $4 \mathrm{~cm})$ :}

Wabe I. Ausbau nach oben u. unten : Blümchen.

Wabe II. Ausbau nach oben : Blümchen.

Ausbau nach unten : Querstellung.

b) Vorgabe von Leitstreifen in Spitzstellung. Ausbau nach oben :

\section{Volk 2 (Abstand 7,5-8,5 cm) :}

Wabe I. Spitzstellung, dann Blümchen.

Wabe II. Anfangs Spitzstellung, dann zu Querstellung gedreht; Übergang : Blümchen

(Leitstreifen : $n=38, \bar{x}=0^{\circ}$, Blümchenmusterbereich : Seite $1: n=68$, $\bar{x}=8,2^{\circ}$, Seite $2: n=79, \bar{x}=32^{\circ}$ ).

Wabe III. Spitzstellung, dann Querstellung (Abb. 9) (Leitstreifen: $\mathrm{n}=24$, $\bar{x}=1,7^{\circ}$; oberer Wabenbereich : $\mathrm{n}=82, \bar{x}=33^{\circ}$ )
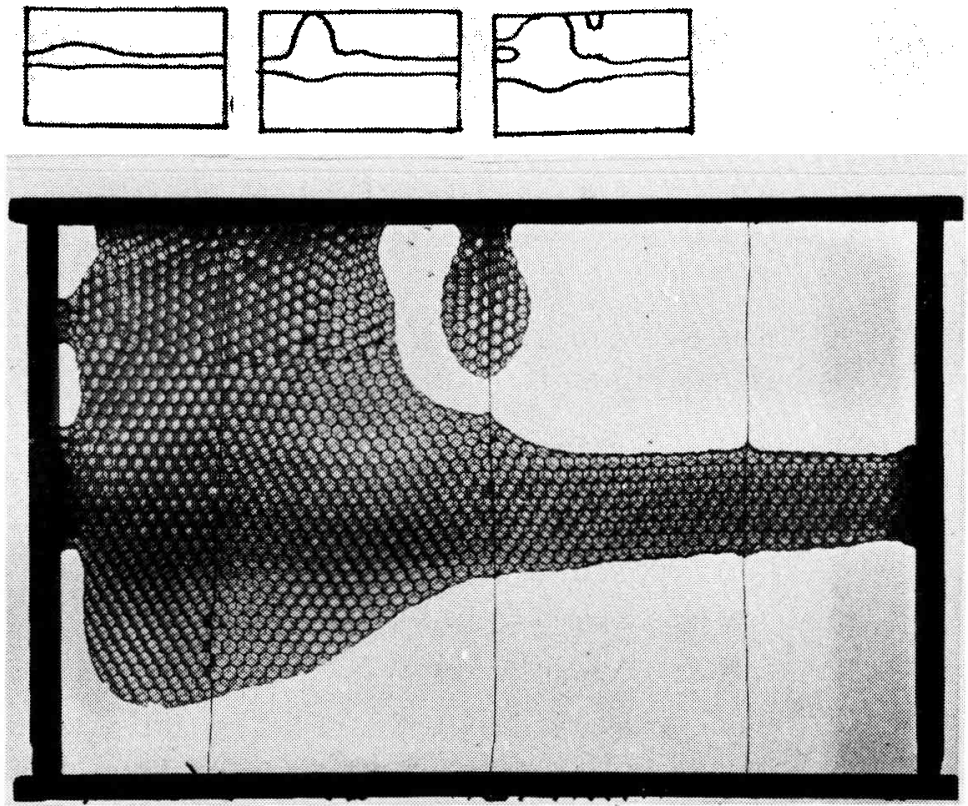

ABв. 9. - Änderung der gebotenen Spitzstellung der Zellen zu Querstellung im oberen Wabenteil; Volk 2. Die Schemazeichungen zeigen die Entstehung der Wabe.

FIG. 9. - Modification de la disposition verticale des cellules, offerte aux abeilles, en disposition transversale dans la partie supérieure du rayon. Colonie 2. Les schémas montrent la formation du rayon. 
Wabe IV. Spitzstellung, dann Querstellung.

Wabe V. Bestehend aus 2 Wabenzungen

a) Querstellung

b) Querstellung.

Volk 3 (Abstand $12 \mathrm{~cm}$ ) :

Wabe I. Querstellung.

(Leitstreifen : $n=25, \bar{x}=0,5^{\circ}$, oberer Wabenbereich : $n=69, \bar{x}=28,8^{\circ}$ )

Wabe II. Spitzstellung.

Wabe III. Spitzstellung, dann Drehen zu Querstellung.

Wabe IV. Spitzstellung.

Wabe V. Spitzstellung.

Volk 4 (Abstand $8 \mathrm{~cm}$ ):

(Ausbau an herausgebrochenen, vertikal stehenden Leitstreifen und an den Resten der Leitstreifen an den Seitenträgern; Abstand dadurch teilweise $16 \mathrm{~cm}$ ).

Wabe I. Spitzstellung und Schrägstellung.

Wabe II. Spitzstellung und Schrägstellung.

Wabe III. Spitzstellung.

c) Vorgabe von Leitstreifen in Schrägstellung. Ausbau nach oben :

Volk 2:

Wabe I. Querstellung.

Volk 3 :

Wabe I. Schrägstellung

(Leitstreifen : $n=30, x=14,5^{\circ}$, oberer Wabenbereich : $n=110, x=16^{\circ}$ )

d) Vorgabe von ungeprägtem Leitstreifen.

Volk 3:

Wabe I. Kein Mauern, nur Wildbau am Oberträger.

Es konnte nicht beobachtet werden, dass sich eine Bautraube an der Stelle gebildet hatte, an der gemauert wurde.

Die geprägten Leitstreifen wurden nach unten immer im vorgegebenen Muster weitergebaut.

Beim Mauern wurde bei $52 \%$ der Bauzungen die vorgegebene Spitzstellung zur Querstellung gedreht.

$$
\text { XI. - Versuchsreihe XI: }
$$

Bauverhalten von Jungbienen, die aus horizontalen Waben geschlüpft sind

1. Material und Methode

a) Versuchsansätze : Volk 1 . 
b) Versuchstiere : Jungbienen, geschlüpft aus horizontalen Plastikwaben mit runden Zellen; 3 Tage vor dem Schlüpftermin Horizontallage der Waben.

c) Volkstärke : 800-1000 Bienen.

d) Beutentyp : kleiner Korb ("Pöttchen »).

e) Rähmchen : keine.

Während ihrer ersten Lebensstunden beliefen die Versuchstiere nur diese, im Raum falsch orientierten Waben. Eine Information über die normale vertikale Stellung der Wabe wurde auf diese Weise ausgeschlossen. Die Bienen hatten auch keine Möglichkeit, sich über die Zellstellung in bezug auf die Schwerkraft zu orientieren.

\section{Ergebnis :}

Nach dem Aufstellen bildeten die Bienen eine Traube am höchsten Punkt des Körbchens. Diese blieb über einen Zeitraum von 8 Tagen bestehen, ohne dass mit dem Wabenbau begonnen wurde. Wespen plünderten das Volk aus, so dass die Beobachtungen nicht über den Zeitraum von 8 Tagen hinausgehen.

\section{DISKUSSION}

Bienen bauen unter normalen Bedingungen verschiedene Zellstellungen. Nach VoN Hessberg (1955) findet man Spitzstellung àm häufigsten. ThOMpson (1930) und FreUdenstein (1937) sind der Ansicht, dass Bienen keiner Zellstellung den Vorzug geben. Die Festigkeit der Waben in Spitz- und Querstellung der Zellen ist gleich gross (Kirchner (aus RuttNer 1974), Wedmore 1929). Nach Vogt (1911) spielt die Tradition beim Wabenbau eine grosse Rolle : junge Bienen bauen nie ohne Vorbild (= alte Bienen) und Erinnerungsbilder (= Waben). Beim Wabenbau eines Schwarms vermutete er, dass die Erinnerung an die Waben des Muttervolkes von Bedeutung ist. Auch RUTTNER (1974) nimmt an, dass beim Wabenbau Lernprozesse eingehen.

Nach Martin und Lindauer (1966) können sich Bienen über die Stellung der Wabenzellen in bezug zur Schwerkraft orientieren. Beim Ausbau der Zellen können Bienen die Stärke der Zellwand messen. Vorausgesetzt, die Dickenmessung des Zellgrundes geschieht auf ähnliche Weise, wie bei Martin und Lindauer für die Zellwand beschrieben, müssten Bienen ausser der Zellstellung auch das Zellgrundmuster einer Wabe mit auf der Spitze stehenden Zellen von dem einer Wabe mit liegenden Zellen und auch dem einer Blümchenwabe unterscheiden können.

Die vorliegenden Untersuchungen zeigen, dass Lernprozesse beim Wabenbau eine Rolle spielen. Das Bauverhalten beruht zwar auf einer genetischen Grundlage, stellt aber keinen starren Verhaltensablauf dar: Bauverhalten ist durch Lernprozesse modifizierbar. Der Lernvorgang ist nicht zwingend auf ein Muster ausgerichtet; andere 
Muster können nebeneinander gebaut werden. Die Versuchsvölker der Versuchsreihe I zeigten eine grosse Bereitschaft zum Bau des Musters, aus dem sie schlüpften und über das sie liefen. Aus Spitzmuster geschlüpfte Jungbienen bauten überwiegend Zellen in Spitzstellung. Bei Bienen, die aus Quermuster geschlüpft waren und diese belaufen hatten, war die Bereitschaft gross, von der normalen Spitzstellung der Zellen abzuweichen. Im Falle der Blümchenmusterzuchtwaben wurden den schlüpfenden Jungbienen "Lernwaben " geboten, deren Zellstellung auf beiden Seiten der Wabe unterschiedlich war. Sie erhielten entsprechend unterschiedliche Informationen über die Stellung der Zellen zur Schwerkraft, je nachdem welche Wabenseite sie beliefen. GONTARSKI (1949) fand im stillstehenden Stock nach vorangegangener Rotation sehr unregelmässigen Wabenbau. Die Bienen machten einen desorientierten Eindruck. Hier änderte sich nach Aussetzen der Rotation der Bezugspunkt "Schwerkraft ". In Versuchsreihe I blieb der Bezugspunkt "Schwerkraft " gleich, die Stellung der Zellen differierte jedoch auf beiden Seiten der Lernwabe, so dass eine eindeutige Beziehung zwischen Zellstellung und Richtung der Schwerkraft für die Bienen nicht ablesbar war. Es ist wahrscheinlich, dass der Bau des Blümchenmusters nicht auf einem Erlernen des komplizierten Zellgrundes oder der beidseitig unterschiedlichen Zellstellung beruht, sondern auf dem Fehlen einer Information über normales Wabenmuster.

Bienen, die aus Waben mit runden Zellen geschlüpft waren, bauten sechseckige Zellen. Alle Wabenmuster, die diese Bienen bauten, hatten sie nie kennengelernt. Betrachtet man die einzelnen Wabenzungen in ihrer Gesamtheit, so gab dieses Bienenvolk keinem Wabenmuster den Vorzug. Auffallend ist die grosse Unregelmässigkeit sowohl des gesamten Wabenmusters, wie auch der einzelnen Elemente : Das Zellgrundmuster ist häufig asymmetrisch, die Zellwände sind schief, die Zellumina unterschiedlich, der Durchmesser der Zellen ändert sich vom Zellgrund zur Zellöffnung hin. Diese Bienen erhielten während der ersten Lebensstunden keine Information über die Form des Sechseckes und dessen Bezug zur Schwerkraft. Da diese Zuchtwaben keine Zellgrundverzahnung aufwiesen, fand auch keine diesbezügliche Prägung statt.

Die Jungbienen (Versuchsreihen I u. II) wurden alle 24 Stunden von den Zuchtwaben abgefegt. Die Zeit zwischen dem Abfegen der Bienen von der Zucht- und Lernwabe und dem eigenen Baubeginn war bei den Völkern unterschiedlich, der Zeitraum zwischen Lernen und Anwenden des Gelernten differierte erheblich. Völker, die unverzüglich die Bautätigkeit aufnahmen, bauten die gleichen oder ähnliche Muster wie die der Lernwabe. Die Bauergebnisse der Völker mit stark verzögertem Baubeginn wichen von den zu erlernenden Zuchtwabenmustern ab. Als Beispiel mögen die aus Quermuster geschlüpften Jungbienen dienen : Bei Volk 2 und 3 (Versuchsreihe I) verzögerte sich der Baubeginn, Volk 4 baute sofort nach dem Aufstellen (Tabelle 2). Es wäre möglich, dass während der grossen Zeitspanne zwischen Lernen und Anwenden des Gelernten Bienen das erlernte Muster "vergessen ». Auch bei Farbdressuren vergessen Bienen die Dressurverknüpfung Farbe und Futter in bestimmter Zeit (MENZEL, 1968). 
Das spontane Auftreten von Unregelmässigkeiten und Abweichungen von der normalen Spitzstellung der Zellen wird häufig dem langsamen Bautempo zugesprochen. Die Versuchsvölker, die beim Wabenbau am ungeprägten Leitstreifen von dem Spitzmuster abwichen, bauten keineswegs langsamer.

Ein Erlernen der Stellung des Sechseckes im Zellverband ist während der ersten Stunden nach dem Schlüpfen möglich. Der Ausbau eines vorgegebenen Musters aber beeinflusst das weitere Bauverhalten nicht. Jungbienen, denen 1. eine BlümchenmusterMittelwand und 2. ein Blümchenmuster-Leitstreifen geboten wurde, bauten anschliessend am ungeprägten Leitstreifen Normalmuster (Versuchsreihe III). Einschränkend muss gesagt werden, dass diese Bienen erst nach Tagen zu bauen begannen und der Zeitpunkt für eine Prägung auf ein Wabenmuster vielleicht verstrichen war.

Die Ergebnisse der Versuchsreihe IV zeigen eine Plastizität des Bauverhaltens und die Fähigkeit der Bienen, sich gegebenen Bausituationen anzupassen und diese sinnvoll weiterzuführen. Wird Jungbienen ein Muster in Form eines geprägten Leitstreifens geboten, so wird dieser im vorgegebenen und nicht im Zuchtwabenmuster ausgebaut. Auch unter normalen Bedingungen setzt jede Biene begonnene Wabenzungen fort und passt ihre Arbeit den Bedürfnissen des Volkes an. Reparaturen an beschädigtem Wabenwerk sind durch diese Anpassung an die Bausituation erst möglich.

Die aus horizontal gelagerten Waben geschlüpften Bienen (Versuchsreihe XI) bildeten zwar eine Traube, bauten aber innerhalb von 8 Tagen nicht. Bei Abbruch des Versuches war die jüngste Biene des Volkes 9 Tage, die älteste 12 Tage alt. Etwa in diesem Alter beginnt normalerweise die Bautätigkeit. Bienen sind aber in der Lage, sich den Bedürfnissen des Volkes anzupassen (RösCH, 1930, LINDAUER, 1952, LAU, 1959). Andere Jungbienenvölker (Versuchsreihe I) bauten bereits in diesem Alter. Das Alter unserer Versuchsbienen erklärt also das Unterlassen des Wabenbaues nicht.

MARTiN und Lindauer (1966) schalteten das Schweresinnesorgan der Biene aus und liessen aus derartig operierten Tieren zusammengesetzte Völkchen bauen. Ohne funktionstüchtiges Nackenorgan war eine Grundorientierung der Wabenzelle unmöglich gemacht, und es entstanden nicht einmal Bauanfänge. Bei unserem Versuch besassen die Bienen einen intakten Schweresinn, bauten aber trotzdem nicht.

Daraus muss man schliessen (vorausgesetzt, sie hätten auch nach 8 Tagen Beobachtungszeit nicht $\mathrm{zu}$ bauen begonnen), dass ihnen eine Orientierung der Wabe und Wabenzellen im Schwerefeld unmöglich war : Sie konnten zwar die Schwerkraft perzipieren, aber nicht in bezug zur Ausrichtung des Wabenbaues setzen. Bei der Vertikalorientierung der Wabe und ihrer Wabenzellen scheinen Lernprozesse von Bedeutung zu sein.

MARTIN (1965) beschreibt, dass sich Bienen olfaktorisch und taktil am Untergrund orientieren. Die Beschaffenheit des Untergrundes ist für Bienen erfassbar und ein wichtiger Orientierungsfaktor. Bienen können optische Eindrücke bei einer 
horizontalen Bewegung (wie z.B. den Flugwinkel) auf ein anderes Bezugssystem, nämlich die Schwerkraft, übertragen. Die taktilen Eindrücke, die sie beim Belaufen einer horizontalen Wabe gewinnen, können sie nicht aus der Horizontalen auf die Vertikale übertragen. Die Herstellung eines Bezuges zur Schwerkraft ist ihnen in diesem Fall nicht möglich. Diese Versuchsreihe wird wiederholt, um klare Ergebnisse zu gewinnen.

Unter besonderen Bedingungen (Versuchsreihe $\mathrm{X}$ ) ist Wabenbau auch in geonegativer Richtung zu beobachten. Nach SENDLER (1940) ist ein freier Raum über bruthaltigen Waben die Vorbedingung für ein Bauen in geonegativer Richtung. In unseren Versuchen war den Bienen sogar nur ein Leitstreifen in der Mitte des Rahmens gegeben worden, der ausserdem auch noch die Möglichkeit bot, nach unten zu bauen.

HUBER (1814) hat genaue Beobachtungen bei der Entstehung der Wabe sowohl beim Mauern als auch bei einem normalen Wabenanfang gemacht. Er fand bei beiden Bauarten die gleiche Arbeitsweise.

Die Bildung einer Bautraube war beim Mauern in diesen Experimenten nicht festzustellen. Hierzu sind entsprechende Beobachtungen notwendig. Es wäre durchaus denkbar, dass Bienen auch ohne Bautraube die Wabe ausbauen können. Beim Wabenbau kommt der Schwerkraft eine grosse Bedeutung zu, da dadurch den Bienen die Orientierung in der Vertikalen ermöglicht wird.

GONTARSKI (1949) vertauschte bei seinen Bauversuchen unter verschiedenen experimentellen Bedingungen durch eine zentralsymmetrische Rotation " oben " und "unten". Die Bienen bildeten keine Bauketten, sondern zogen sich zu "Bienenklümpchen" zusammen. Trotzdem wurde eine normale Wabe gebaut. Das Bauen unter diesen Bedingungen würde dem Mauern entsprechen. Bei dieser Art des Wabenbaues wurde bei ca. $50 \%$ der Bauzungen die vorgegebene Zellstellung verändert. Da diese Musterveränderung nur beim Mauern und nicht beim Bauen am unteren Rand des Leitstreifens auftritt, ist anzunehmen, dass dies auf die veränderten Baubedingungen beim Mauern zurückzuführen ist. Am ungeprägten Leitstreifen wurde nicht " gemauert ». Vielleicht fehlte der Reiz des geprägten Leitstreifens, um die Bienen wie in den anderen Versuchen zum Mauern zu veranlassen.

Nach UlRICH (1964) wird die Wabe als Gefüge gebaut, d.h. sie entsteht als Ganzes. Es wird nicht Zelle an Zelle gesetzt, nur im Zellverband entsteht ein regelmässiges Sechseckmuster. Am Wabenanfang und am Rand der Bauzunge werden Wachstupfen angesetzt, die dann seitliche Vertiefungen ("Kuhlen ") erhalten. Durch die Art, wie diese Kuhlen auf beiden Seiten angesetzt und ausgearbeitet werden, wird die Verzahnung der Zellböden festgelegt. Daraus ergibt sich das Wabenmuster. Nach HUBER (1814) werden bei der Anlage der Zellen am Wabenanfang die Zellwände festgelegt, bevor der Boden der Zelle überhaupt fertig ist.

Versuchsreihe IX zeigt, dass der Zellgrund normalerweise das mustergebende Element der Wabe ist. Teilweise orientierten sich die Bienen aber an der Zellstellung bereits ausgebauter Wabenabschnitte und bauten sinngemäss weiter. Zellen ohne 
geprägten Zellgrund wurden mustergerecht angelegt. Normalerweise wächst die Wabe als Ganzes. Unter veränderten Bedingungen können aber Teile, wie die Zellwände, mustergerecht auf glattem Grund angebracht werden und damit das Wabenmuster bestimmen. Das Wabenmuster kann Seite für Seite unabhängig angelegt werden. Dabei wird sogar die Zweischichtigkeit der normalen Bienenwabe aufgegeben und ein Wabenabschnitt einschichtig angelegt (Versuchsreihe VIII). Bienen bauen auch dann regelmässige Prismen, wenn am Rand der Bautraube der Kontakt gestört ist. Die Anlage der Zellwände auf glatter Wand erfolgte in Sechseckform, eine "Rundzellenphase " wurde nicht beobachtet.

Betrachtet man den Zellboden beim Blümchenmuster, so treten schon bei ganz sauber gebautem Blümchenmuster sehr viele verschiedene Zellbodenstrukturen auf. Die Möglichkeiten erhöhen sich noch, wenn Bienen durch unsaubere Zellstellung Blümchenmuster bauen (Abb. 10).
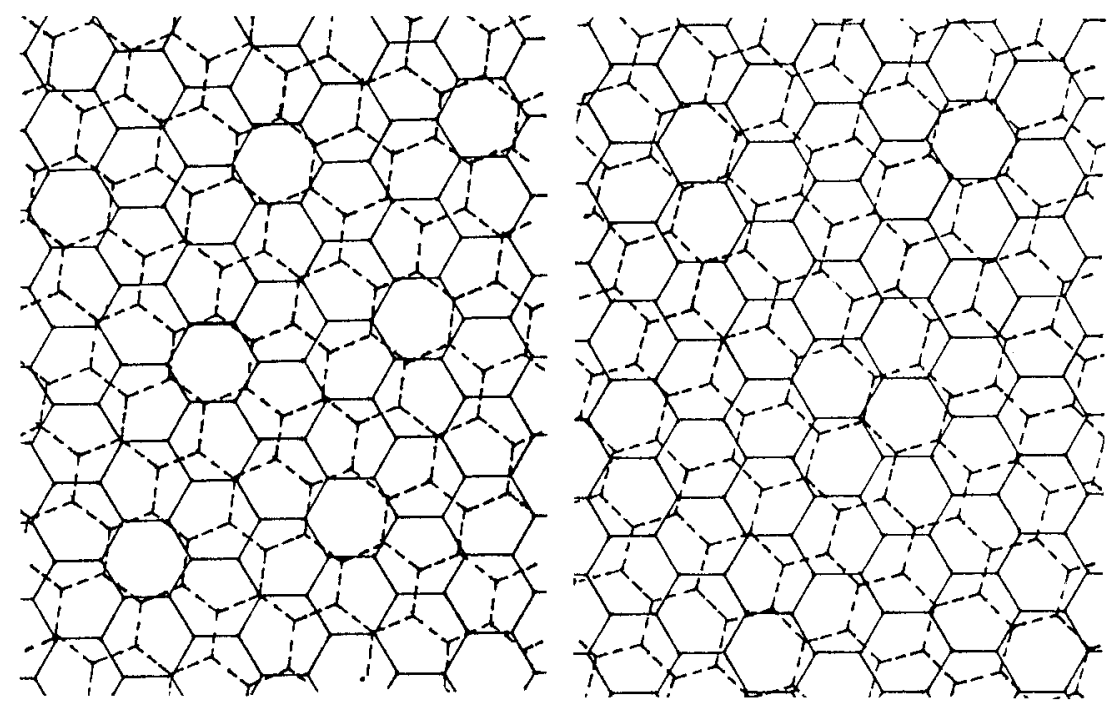

Авв. 10. - Unterschiedliche Anordnung der "Blümchen" durch geringe Drehung der Zellen in Querstellung.

FIG. 10. - Disposition différente des "fleurs "par suite d'une légère rotation des cellules en position transversale.

Es ist schwer vorstellbar, dass Bienen dieses so komplizierte Zellgrundmuster ohne Orientierungshilfe anlegen können und die Zellwände nur "ausziehen". Als Alternative ist denkbar, dass der Zellboden bei der Anlage der Zellwände determiniert wird.

Bei der Entstehung einer Blümchenmusterwabe wird als erstes der Zellgrund abgerundet angelegt. Das Zellgrundmuster ergibt sich erst aus dem Ansetzen der Zellwände, die Wabenseite für Wabenseite gebaut werden. Das Zellgrundmuster ergibt 
sich dann als Kompromiss aus dem Zellgrundmuster der Spitzstellung der Zellen auf der einen Wabenseite und der Querstellung auf der anderen Seite. Durch die Arbeitsweise der Baubienen, die unabhängig voneinander arbeiten, ist die Möglichkeit gegeben, zu diesem Kompromiss zu kommen. Die Baubiene am Rand der Wabenzunge hat eine Information über das vorhandene Muster durch die Zellstellung der letzten Zellreihe. Die normale Zellbodenverzahnung wird aufgegeben, die gleichmässige Prismenverzahnung dagegen bleibt erhalten. KoENiger (mündl. Mitteilung) erhielt dieses Muster, wenn er Bienen durch kleine Manschetten an den Vorderbeinen behinderte. Bei LAU (1959) war es die Folge der Amputation eines Vorderbeines.

In Versuchsreihe VII zeigt sich, dass die Jahreszeit einen Einfluss auf die Bautätigkeit beim Blümchenmuster hat, nämlich dass die Bienen dieses Muster im Spätsommer (ab August) weiterführen, während sie vorher überwiegend zum Normalmuster drehen. Nach Rösch (1927) werden zur Hauptbauzeit (Mai/Juni) die Waben am schnellsten erstellt. Die Baulust ist wohl dadurch begründet, dass das Bienenvolk zu dieser Zeit auf dem Höhepunkt seiner Entwicklung ist. Bienen passen sich dem vorgegebenen Blümchenmuster leichter an, wenn die Baulust schwächer wird. Beim Ausbau der Blümchenmuster-Leitstreifen wurde die vorgegebene Zellstellung sowohl zur Quer- als auch zur Spitzstellung gedreht, z.T. mehrmals unterschiedlich auf einer Wabe. Eine bevorzugte Drehrichtung liegt nicht vor. Der Ausbau des Blümchenmusters ist unabhängig von der Häufigkeit des vorangegangenen Blümchenmuster-Ausbaues. Auch die Breite der Leitstreifen $(1-4 \mathrm{~cm})$ zeigt keinen Einfluss. Aber Blümchenmuster-Leitstreifen, die nur eine Zellreihe breit waren, wurden nicht als mustergebend angenommen, sondern beim Ausbau wie eine Reihe Heftzellen korrigiert. Jeder freie Wabenbau weist am Ansatz Unregelmässigkeiten auf, die sich über mehrere Zellreihen erstrecken können (bei Wabenzungen aus Baurahmen der Standvölker war nach 1-5, im Mittel 3 Heftzellreihen ein regelmässiges Muster erreicht). Breitere Blümchenmuster-Leitstreifen wurden von den Versuchsvölkern überwiegend mustergerecht ausgebaut. Sie liegen in ihren Abmessungen über der durchschnittlichen Heftzellreihenbreite.

\section{DANK}

Wir danken Frau Dr. I. JUNG-HOFFMANN, Herrn Prof. Dr. B. SCHRICKER und Frau E. GEISELER für ihre Unterstützung. 


\section{RÉSUMÉ}

Si l'on considère des rayons qui ont été construits librement, on s'aperçoit que la disposition des cellules est loin d'être aussi uniforme que cela apparaît au premier coup d'œil. A côté de la position "normale " avec 2 parois verticales (Fig. 1 a), on rencontre des cellules en position transversale, avec 2 parois horizontales (Fig. $1 c$ ), et d'autres en position oblique (Fig. $1 b$ ); l'hexagone est l'élément commun à toutes les cellules. Ces dispositions peuvent toutes être réalisées par une colonie et se rencontrent souvent sur un même rayon. La pr ition verticale est la plus courante dans les rayons construits librement, c'est-à-dire que l'axe principal de la cellule coïncide dans le cas idéal avec la verticale. Les constructions transversales, dans lesquelles l'axe principal des cellules forme dans le cas idéal un angle de $30^{\circ}$ avec la verticale, se rencontrent de façon spontanée dans environ $5 \%$ des cas. Il existe aussi tous les intermédiaires entre ces deux positions (position oblique, Fig. 1 b).

Dans de très rares cas apparaît une forme mixte entre la position verticale et la position transversale. Une face du rayon correspond à la position normale verticale, tandis que l'autre face présente une disposition des cellules décalée de $30^{\circ}$ par rotation. Comme à partir de toute autre rotation de la position des cellules d'une face par rapport à l'autre, il s'ensuit une configuration de base qui comporte divers types de cellules se répétant régulièrement. Cette configuration est désignée par le terme " configuration florale ". Par transparence on voit une configuration dans laquelle 2 fonds de cellule reposent exactement l'un sur l'autre et forment ainsi le "cœur de la fleur ». Par suite du décalage les cellules contiguës apparaissent comme les "pétales" (Fig. 1d).

On a étudié le comportement de construction des abeilles au cours de l'établissement de différentes configurations de rayon. Il s'agissait de trouver si l'établissement de la configuration était inné ou acquis. En outre on a recherché dans quelle mesure la pesanteur avait une influence sur l'alignement de la configuration lors de la construction du rayon et quelles modifications survenaient quand la construction avait lieu dans la direction géonégative.

Les colonies expérimentales étaient constituées d'essaims naturels ou artificiels composés d'une population normale sous le rapport de l'âge; on a par ailleurs utilisé des colonies de jeunes abeilles (insectes éclos en étuve). Dans chaque expérience les rayons d'élevage présentaient une configuration différente. Ils ont été mis en place principalement dans des nuclei à 3 ou 5 cadres. On a collé sur les petits cadres des amorces de cire avec ou sans empreinte de cellules ou des feuilles de cire gaufrée (avec la configuration verticale, transversale, oblique ou florale). Les feuilles de cire gaufrée à configuration florale, qui présentent sur une face une disposition verticale des cellules et sur l'autre une disposition transversale, ont été fabriquées à la demande.

1. De jeunes abeilles, écloses à partir de rayons d’élevage de configuration variée, ont achevé la construction d'amorces de cire sans empreinte. La comparaison entre les résultats de construction obtenus par ces colonies et la configuration des cadres d'élevage montre que le processus d'apprentissage joue un rôle dans la construction des rayons. Les abeilles semblent reconnaitre et mémoriser la configuration des rayons d'où elles naissent et qu'elles parcourent : elles construisent de préférence selon cette configuration. De jeunes abeilles, écloses de rayons en plastique avec des cellules rondes, construisent toutes les configurations de rayons qui existent. Aucune disposition de cellules n'est privilégiée, et sur les deux faces du rayon également des dispositions différentes de cellules se rencontrent. Les abeilles, qui n'ont jamais appris à reconnaitre la configuration hexagonale des cellules construisent malgré tout des cellules hexagonales (Fig. 3-5; Tabl. 1-3; Diagrammes 1-7).

2. De jeunes abeilles, auxquelles on a offert des rayons avec différentes configurations comme " base d'apprentissage ", achèvent néanmoins la construction d'amorces de cire ayant reçu différentes empreintes : l'adaptation aux situations présentes de la construction l'emporte sur la configuration qui peut s'apprendre (Fig. 7).

3. L'acceptation de la configuration florale chez les colonies, dont la composition sous le rapport de l'âge est normale, dépend de la saison : à la pleine période de construction (mai-juin) la configuration florale est en majorité transformée en configuration normale, tandis qu'en fin de saison (à partir d'août environ), cette configuration est presqu'exclusivement maintenue (Fig. 8). 
4. Dans des conditions de construction atypiques, ce n'est pas le fond de la cellule mais sa disposition qui détermine la configuration du rayon. La configuration hexagonale régulière est alors maintenue même s'il n'existe aucune empreinte de fond de cellule et si un engrenage avec le fond des cellules de l'autre face n'est pas possible. Dans ce cas seules des parois de cellules sont posées sur un support lisse avec un engrenage prismatique régulier.

5. Lors de la formation d'un rayon à configuration florale les parois des cellules sont les éléments qui induisent la configuration. Lors de la construction de cette configuration, les abeilles s'orientent d'après la disposition des cellules de la dernière rangée de chacune des faces et non d'après le fond de la cellule. Puisque les abeilles s'efforcent de parvenir à un engrenage prismatique régulier, dans le cas d'une configuration florale un compromis permet de construire un fond de cellule qui rend possible une disposition différente des cellules sur les deux faces du rayon.

6. Les abeilles construisent selon la direction géonégative ("maçonnage »), lorsqu'on leur offre au milieu du cadre des ébauches de cire laissant un grand intervalle entre le haut et le bas du cadre. Une modification de la disposition des cellules avait lieu alors dans $50 \%$ des portions de rayons ainsi formés, modification qu'il faut éventuellement attribuer à une modification de la référence à la pesanteur. Lors de la construction du bord inférieur de l'amorce de cire la disposition des cellules existante est maintenue (Fig. 9).

7. On décrit un protocole d'expérience qui devrait permettre de tester le comportement de construction d'abeilles qui sont nées de rayons en plastique disposés horizontalement avec des cellules rondes.

\section{LITERATURVERZEICHNIS}

Armbruster L., 1920. - Zum Problem der Bienenzelle. Eine vergleichende Instinktbiologie des Nestbaues bei Bienen und Wespen. Bücherei für Bienenkunde 4. Leipzig, Berlin, Freiburg/Br.

FreUdenstein K., 1937/38. - Die Wachserzeugung und der Wabenbau im Bienenvolk. Disch. Imkerführer 11 (6), 154-156.

GonTARsKı H., 1949. - Ûber die Vertikalorientierung der Bienen beim Bau der Waben und bei der Anlage des Brutnestes. Z. vergl. Physiol. 31, 652-670.

Hessberg H.V., 1955. - Messungen an natürlichen Waben. Arch. Bienenkd. 32, 50-52.

Hubse W., 1957. - Beobachtungen zum Wabenbau der Honigbiene Apis mellifica L. Arch. Geflügelz. Kleintierkd. 6 (5/6), 343-358.

Huber F., 1814. - Nouvelles observations sur les abeilles. Bd. 2, Deutsche Übersetzung von G. Kleine (1869).

Kalmus H., 1937. - Versuche über die Orientierung der Biene im Stock. Z. vergl. Physiol. 24, 166-187.

KePler J., 1939. - Harmonices mundi. (1619). Frankfurt/M. : G. Tampach, Gesamtausgabe Bayr. Acad. Wiss. Bd. 5, München und Berlin.

LAU D., 1959. - Beobachtungen und Experimente über die Entstehung der Bienenwabe (Apis mellifica). Zool. Beitr. 4, 233-306.

Lindauer M., 1952. - Ein Beitrag zur Frage der Arbeitsteilung im Bienenstaat. Z. vergl. Physiol. 34, 299345.

Lindauer M. und Nedel J. O., 1959. - Ein Schweresinnesorgan der Honigbiene. Z. vergl. Physiol. 42, 334-364.

MaibaCh E., 1935. - Harmonie ist alles! Schweiz. Bienenztg. 71 (N.F. 58), 473-474.

Maraldi G. F., 1712. - Observations sur les abeilles. Hist. Acad. roy. Sci. Paris.

MARKL H., 1966. - Schwerkraftdressuren an Honigbienen. I. Die geomenotaktische Fehlorientierung. II. Die Rolle der schwererezeptorischen Borstenfelder verschiedener Gelenke für die Schwerekompassorientierung. Z. vergl. Physiol. 53, 328-371.

Martin H., 1965. - Leistungen des topochemischen Sinnes bei der Honigbiene. Z. vergl. Physiol. 50, 254292. 
MARTIN H. und LiNDaUer M., 1966. - Sinnesphysiologische Leistungen beim Wabenbau der Honigbiene. Z. vergl. Physiol. 53, 372-404.

Menzel R., 1968. - Das Gedächtnis der Honigbiene für Spektralfarben. I. Kurzzeitiges und langzeitiges Behalten. Z. vergl. Physiol. 60, 82-102.

Meretz W., 1963. - Die Wabenzelle der Honigbiene. Bull. math. Biophys. 25, 1, 95-110.

Pohl P., 1939. - Zur Statik der Bienenwabe. Arch. Bienenkd. 20, 1-5.

QuELLE F., 1923. - Das Rätsel des Wabenbaues bei Apis mellifica. Dtsch. Entomol. Zeitschrift, 319-331.

Rösch G. A., 1927. - Uber die Bautätigkeit im Bienenvolk und das Alter der Baubienen. Weiterer Beitrag zur Frage nach der Arbeitsteilung im Bienenstaat. Z. vergl. Physiol. 6, 265.

Rôśch G. A., 1930. - Untersuchungen über die Arbeitsteilung im Bienenstaat. II. Die Tätigkeit der Arbeitsbienen unter experimentell veränderten Bedingungen. Z. vergl. Physiol. 12, 1-71.

Ruttner F., 1974. - Uber das Muster der Bienenwabe. Apidologie. 5, 3, 296-297.

SACHS L., 1974. - Angewandte Statistik. Springer, Berlin.

SChröder H., 1950. - Geometrie der Bienenzelle. Arch. Bienenkd. 27, 38.

Schuster A., 1956/57. - Der Zellenbau der Honigbiene als mathematisches Problem. Jahresbericht der Oberrealschule in Wunsiedel.

SeNDLER O., 1940. - Wann baut die Honigbiene ihre Wabe in entgegengesetzter Richtung? Natur und Volk 70, 539-542.

THOMPSON F., 1930. - Observations of the position of hexagons in natural comb building. Bee World 11, 107.

Ulrich W., 1964. - Geometrie und Entstehung der Bienenwabe. Z. Bienenforsch. 7, 62-71.

VOGT H., 1911. - Geometrie und Ökonomie der Bienenzelle. Trewendt und Garnier, Breslau. Festschrift zur Jahrhundertfeier der Universität Breslau 1911.

Wedmore E. B., 1929. - The Building of Honey Comb. Bee World 4, 53.

WeIss K., 1958. - Über die künstliche Mittelwand aus Wachs. Imkerfreund 13 (6), 171-174.

Le Directeur de la publication : J. LouvEAUX

Imprimerie de Montligeon (Orne) - Dépôt légal no 10247

CCPAP. AD EP O 117 